\title{
REVISÃo TAXONÔMICA DO GÊNERo CURTIA (GENTIANACEAE) ${ }^{1}$
}

\author{
Sônia Regina de Melo Crespo ${ }^{2}$ \& Washington Marcondes-Ferreira ${ }^{3}$
}

\begin{abstract}
Resumo
(Revisão taxonômica do gênero Curtia (Gentianaceae)) A presente revisão do gênero Curtia (Gentianaceae) a qual inclui chave de identificação, descrições, ilustrações e sinônimos, reconheceu oito espécies: $C$. ayangannae, C. conferta, C. diffusa, C. obtusifolia, C. quadrifolia, C. tenella, C. tenuifolia e C. verticillaris. Curtia é um gênero neotropical, tendo o Brasil como seu centro de diversidade. Curtia tenella e C. tenuifolia têm ampla distribuição geográfica, ocorrendo nas Américas Central e do Sul, C. obtusifolia e C. quadrifolia concentram-se na região amazônica e $C$. ayangannae está restrita à Guiana. As demais espécies ocorrem no Brasil, distribuídas desde a Região Nordeste até a Região Sul. A distilia foi confirmada em C. obtusifolia e a tristilia em C. tenuifolia.
\end{abstract}

Palavras-chave: heterostilia, morfologia, neotrópico, taxonomia.

\section{Abstract}

(Taxonomic revision of the genus Curtia (Gentianaceae)) The current revision of the genus Curtia (Gentianaceae), which includes a key for identification, descriptions, illustrations and synonyms, recognized eight species: C. ayangannae, C. conferta, C. diffusa, C. obtusifolia, C. quadrifolia, C. tenella, C. tenuifolia, and C. verticillaris. The genus is Neotropical with its diversity center in Brazil. Curtia tenuifolia and C. tenella have wide geographic distribution, occurring in Central and South America, C. obtusifolia and C. quadrifolia are concentrated in the Amazonian region, and C. Ayangannae is restricted to Guyana. The other species occur in Brazil, from the Northeast to the South Region. Curtia obtusifolia has been confirmed as a distylous species and C. tenuifolia as a tristylous species.

Key words: heterostily, morphology, neotropics, taxonomy.

\section{INTRODUÇÃo}

O gênero Curtia foi descrito por Chamisso e Schlechtendal em 1826. Martius (1827) transferiu o gênero, que contava apenas com C. gentianoides Cham. \& Schltdl., para Schuebleria Mart. e, descreveu cinco novas espécies (S. conferta Mart., S. diffusa Mart., S. patula Mart., S. stricta Mart. e S. tenella Mart.). Schuebleria foi estudado como um todo por Progel (1865). Knoblauch (1894) restabeleceu Curtia e, a partir de então, esse nome têm sido amplamente utilizado (e.g. Elias \& Robyns 1975; Fabris \& Klein 1971; Maguire 1981; Cordeiro 1987).
Na classificação de Struwe \& Albert (2002) para Gentianaceae, Curtia foi posicionado na tribo Saccifolieae, ao lado de Hockinia Gardner, Saccifolium Maguire \& Pires, Tapeinostemon Benth. e Voyriella Miq. As características principais da tribo são: flores 4-6-meras, com corola tubulosa, pólen em mônades, ausência de disco na base do ovário e heterostilia em algumas espécies.

Curtia é neotropical, composto por espécies herbáceas, com até $1 \mathrm{~m}$ de altura e flores pequenas, brancas, róseas, lilás, azuladas ou roxas, que habitam campos rupestres ou mais raramente cerrados. A heterostilia ocorre

Artigo recebido em 04/2008. Aceito para publicação em 03/2009.

${ }^{1}$ Parte da tese de doutorado da primeira autora, apresentada ao Instituto de Biologia, Depto de Botânica, Universidade Estadual de Campinas.

${ }^{2}$ Universidade Estácio de Sá, campus Vargem Pequena, Est. Boca do Mato, 850, 22783-325, Rio de Janeiro, RJ, Brasil. Autor para correspondência: so.crespo@bol.com.br

${ }^{3}$ Universidade Estadual de Campinas, Instituto de Biologia, Departamento de Botânica, Cidade Universitária Zeferino Vaz, C.P. 6109, 13083-971, Campinas, SP, Brasil.marconde@unicamp.br 
em algumas espécies e já foi mencionada para o gênero por Knoublauch (1894), Gilg (1938) e Cordeiro (1987). No Brasil, o gênero está presente em todas as Regiões.

Foram reconhecidas oito espécies no gênero. As principais características para distingui-las são: forma das folhas e do tubo corolino, ponto de inserção dos filetes, indumento do tubo corolino, morfologia do conectivo das anteras e forma do estigma. A tristilia foi confirmada em C. tenuifolia e a distilia em C. obtusifolia, as demais espécies são homostílicas.

\section{Material e Métodos}

\section{Área de estudo}

A identificação dos materiais foi realizada por comparação com exsicatas, fotografias ou fotocópias dos tipos e com base nas obras originais. Foram examinadas coleções dos herbários B, BHCB, BM, BR, C, CGE, F, G, GFJP, HB, HUEFS, IAN, IPA, K, L, M, NY, R, RB, SP, SPF, UB, UEC, US e VIC.

Para obtenção de medidas dos caracteres vegetativos, foram selecionados 7 a 15 materiais para cada espécie, de acordo com a disponibilidade, buscando abranger a variação da espécie. Destes, 5 a 12 materiais por espécie foram selecionados para obtenção de medidas dos caracteres florais e dos frutos.

A terminologia para caracteres florais, hábito e filotaxia está baseada em Stearn (1992) e para tipos de inflorescência, prefloração do cálice e da corola e placentação segue Weberling (1992). O estudo da venação foliar e da epiderme segue o proposto por Johansen (1940); as folhas de dois espécimes de cada espécie foram diafanizadas, desidratadas em etanol, coradas em safranina alcoólica e montadas em bálsamo sintético Entelam. A terminologia utilizada para a venação, forma e textura foliares está baseada em Hickey (1973), o tipo de estômato em Fahn (1990) e Metcalfe \& Chalk (1979). Foram utilizados microscópio estereoscópico Olympus DF e microscópio óptico Zeiss, com régua micrométrica.

\section{Resultados e Discussão}

Curtia Cham. \& Schltdl., Linnaea 1: 209. 1826. Espécie-tipo: Curtia gentianoides Cham. \& Schltdl.

Schuebleria Mart., Nov. Gen. sp. pl. 2: 113. 1827, nom. superfl.

Apophragma Griseb., Gen. sp. Gent.: 163. 1839. Espécie-tipo: Apophragma tenuifolium (Aubl.) Griseb. (Exacum tenuifolium Aubl.)

Erva; caule ereto, verde ou vináceo (prateado em C. ayangannae), anguloso, simples ou ramificado; ramos ascendentes, retos ou arqueados, glabros, ou com tricomas simples, às vezes presentes na base do caule; entrenós geralmente maiores do que o comprimento das folhas. Folhas simples, sésseis a atenuadas na base, opostas ou 3-7 folhas por nó, patentes, frequentemente reflexas; lâminas foliares simétricas, membranáceas a levemente cartáceas, verdes ou vináceas, glabras, oblongas, elípticas ou ovadas, com ápice agudo, acuminado ou obtuso, margens inteiras; venação acródroma; profilos semelhantes às folhas quanto a forma, textura e venação; tricomas pluricelulares presentes na face adaxial e próximo à base das folhas e profilos. Inflorescências terminais, dicásios simples ou compostos. Flores monoclinas, actinomorfas, diclamídeas, pentâmeras, tristílicas, distílicas ou homostílicas, pediceladas ou curto-pediceladas; pedicelos verdes ou vináceos, angulosos. Cálice formado por sépalas verdes ou vináceas, conatas na base em tubo curto; lacínios iguais em comprimento, lanceolados a estreito-ovados, com prefloração imbricada quincuncial, espessados no dorso, com margens membranáceas, hialinas, ápice acuminado e margens inteiras ou denticuladas. Corola gamopétala, com prefloração imbricada dextrorsa, membranácea, branca, amarela, rosa, lilás, azul, roxa ou tubo branco ou amarelo com lobos róseos ou lilás; tubo reto (às vezes estreitado no ápice ou levemente expandido na região mediana) ou infundibuliforme, piloso na região mediana internamente ou glabro. 
Androceu isostêmone, estames alternipétalos; filetes basifixos, membranáceos, planos, hialinos, inseridos no tubo corolino na mesma altura; anteras inclusas, raramente com ápice ultrapassando levemente o tubo corolino, bitecas, basifixas, eretas, rimosas, oblongas ou lineares, tecas frequentemente estreitadas nas extremidades, prolongadas abaixo do ponto de inserção do filete, introrsas e livres (nas formas brevistilas e mesostilas de espécies heterostílicas e em espécies homostílicas) ou extrorsas e conatas (nas formas longistilas), quando conatas formam um tubo ao redor do estilete; conectivo prolongado ou não acima das tecas, quando prolongado é membranáceo, inteiro, com ápice agudo ou obtuso ou, nos espécimes longistilos de $C$. tenuifolia, frequentemente 2-3-lobado. Gineceu com ovário súpero, bicarpelar, unilocular, ovado ou oblongo, placentação parietal, com ramos profusos para o interior do lóculo; estilete terminal, inteiro, cilíndrico, glabro; estigma bilamelar, com ramos lineares, oblongos, subglobosos, globosos ou capitados, incluso ou ultrapassando levemente o ápice do tubo corolino; papilas estigmáticas lineares, oblongas ou subglobosas. Fruto capsular, septicida, 2valvar, deiscente ainda preso aos ramos, e liberado com o cálice e estilete persistentes e corola decídua ou, em C. quadrifolia, cápsula liberada dos ramos ainda fechada a parcialmente deiscente, sem o cálice, o qual permanece preso aos ramos; cápsula oblonga ou ovada, coriácea a cartácea, apresentando um eixo central onde prendem-se as sementes ou, apenas em $C$. obtusifolia e C. quadrifolia, eixo central ausente e sementes dispostas nas paredes da cápsula. Sementes pequenas, em geral numerosas, ovaladas, globosas ou prismáticas; testa membranácea, com epiderme externa com células em arranjo reticulado.

A diafanização das folhas mostrou que, em Curtia, elas são compostas de três nervuras principais basais perfeitas. A epiderme na face abaxial apresenta células de contorno lobado, com paredes anticlinais sinuosas, e estômatos do tipo anomocíticos (ou ranunculáceos) e diacíticos, com 2-4 células subsidiárias. Na face adaxial, ela é desprovida de estômatos, com células levemente maiores, de contorno lobado a isodiamétrico e paredes anticlinais fracamente sinuosas até aproximadamente retas.

Curtia ocorre principalmente em campos rupestres, mas também em cerrados, em campos e beira de matas ciliares e várzeas.

\section{Chave para identificação das espécies de Curtia}

1. Folhas oblongas (lineares a estreito-oblongas).

2. Conectivo das anteras prolongado acima das tecas; corola infundibuliforme

7. C. tenuifolia

2'. Conectivo das anteras não prolongado acima das tecas; corola tubulosa, freqüentemente estreitada no ápice 6. C. tenella

1'. Folhas elípticas (elípticas a suborbiculares) ou ovadas (lanceoladas a amplo-ovadas).

3. Conectivo das anteras prolongado acima das tecas.

4. Filetes com o dobro do comprimento das anteras ou maiores, inseridos próximo da base ou no terço basal do tubo corolino 8. C. verticillaris

4'. Filetes menores ou com comprimento aproximadamente igual ao das anteras, inseridos na região mediana ou na metade apical do tubo corolino.

5. Tubo corolino estreitado no ápice, internamente glabro

2. C. conferta.

5'. Tubo corolino reto, não estreitado no ápice, internamente piloso na região mediana 3. C. diffusa

3'. Conectivo das anteras não prolongado acima das tecas.

6. Folhas 3 ou 4 por nó; fruto liberado sem o cálice persistente 
6’. Folhas 2 por nó, ou aglomeradas no ápice dos ramos; fruto liberado com cálice persistente.

7. Folhas suborbiculares, curto-pecioladas

1. C. ayangannae

7’. Folhas ovadas, amplo-ovadas, estreito-ovadas ou lanceoladas, sésseis 4. C. obtusifolia

1. Curtia ayangannae L. Cobb \& Jans.-Jac., Blumea 52(1): 5. 2007. Tipo: GUIANA. CuyuniMazaruni, Monte Pakaraima, 3.XI.1992, B. Hoffman \& T. Henkel 3222 (holótipo U n.v.; isótipos NY n.v., US n.v.).

Fig. 1

Essa espécie foi publicada quando a revisão do gênero já havia sido concluída. Cobb et al. (2007), no entanto, apresentaram uma descrição detalhada e ilustrações do hábito, flor e fruto de $C$. ayangannae, além de elétron-micrografias e análise dos seus grãos de pólen. Esse material é suficiente para reconhecê-la como uma espécie distinta das outras sete reconhecidas para Curtia até então, neste estudo.

Curtia ayangannae é um arbusto com caule 4-angulado, folhas opostas, frequentemente aglomeradas no ápice dos ramos, subcoriáceas, suborbiculares, com ápice obtuso. As flores são 5-meras, com sépalas conatas na base, violáceas, corola urceolada a campanulada, violácea ou alaranjada e os frutos cápsulas com o cálice persistente.

2. Curtia conferta (Mart.) Knobl., Bot. Centralbl. 60(11): 357. 1894. Schuebleria conferta Mart., Nov. Gen. sp. pl. 2: 115; tab. 186, fig. 2. 1827. Tipo: BRASIL. MINAS GERAIS: Serro Frio, 1818, C. F. P. Martius s.n. (lectótipo Nov. Gen. sp. pl. 2: tab. 186, fig. 2, aqui designado).

Figs. 2, 3

Curtia confusa Grothe \& Maas, Proc. Kon. Ned. Akad. Wetensch., C 87(1): 42. 1984. Tipo: BRASIL. PARANÁ: Fernandez Pinheiro, 50³0’W, 25³0’S, 26.II.1904, fl., P. Dusén 4392 (holótipo S n.v. - fotografia UEC; isótipo S n.v. fotografia UEC), syn. nov.

Ervas, 10,5-50 cm alt.; caule 6-12angulado, 0,4-1,9 mm diâm.; entrenós 3-35 mm compr. Folhas 3-7 por nó, 3,5-8,8 × 1,74,5 mm, elípticas (estreito-elípticas ou elípticas)

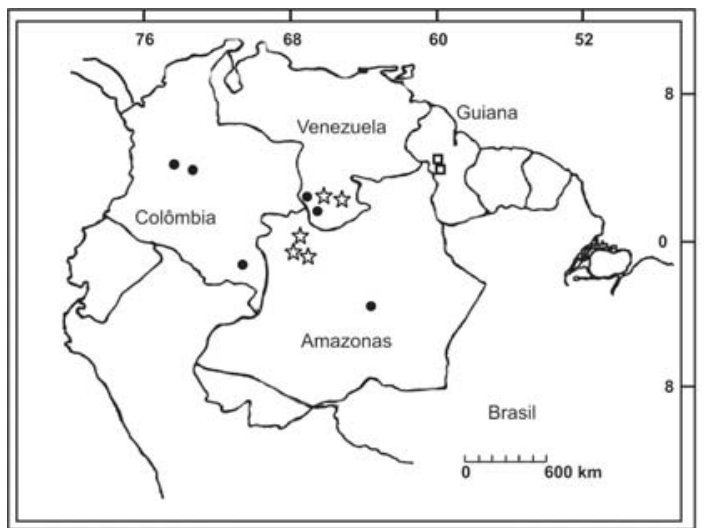

Figura 1 - Mapa de distribuição geográfica de Curtia ayangannae L. Cobb \& Jans.-Jac. ( $\square$ ), C. obtusifolia (Spruce ex Benth.) Knobl. (支) e Curtia quadrifolia Maguire (

Figure 1 - Geographic distribution of Curtia ayangannae L. Cobb \& Jans.-Jac. ( $\square$ ), C. obtusifolia (Spruce ex Benth.) Knobl. (支) and Curtia quadrifolia Maguire (O)

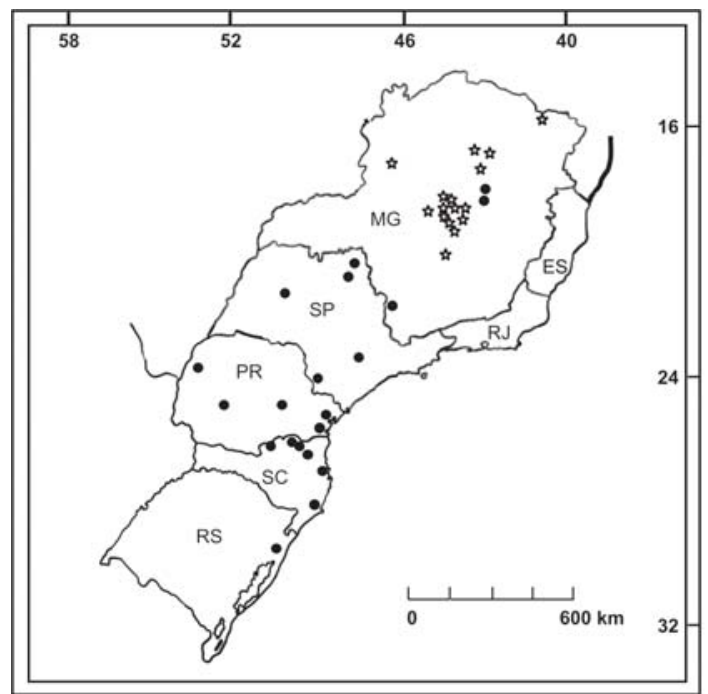

Figura 2 - Mapa de distribuição geográfica de Curtia conferta (Mart.) Knobl. e C. diffusa (Mart.) Cham. (负).

Figura 2 - Geograhic distribution of Curtia conferta (Mart.) Knobl. (O) and C. diffusa (Mart.) Cham. (察). 

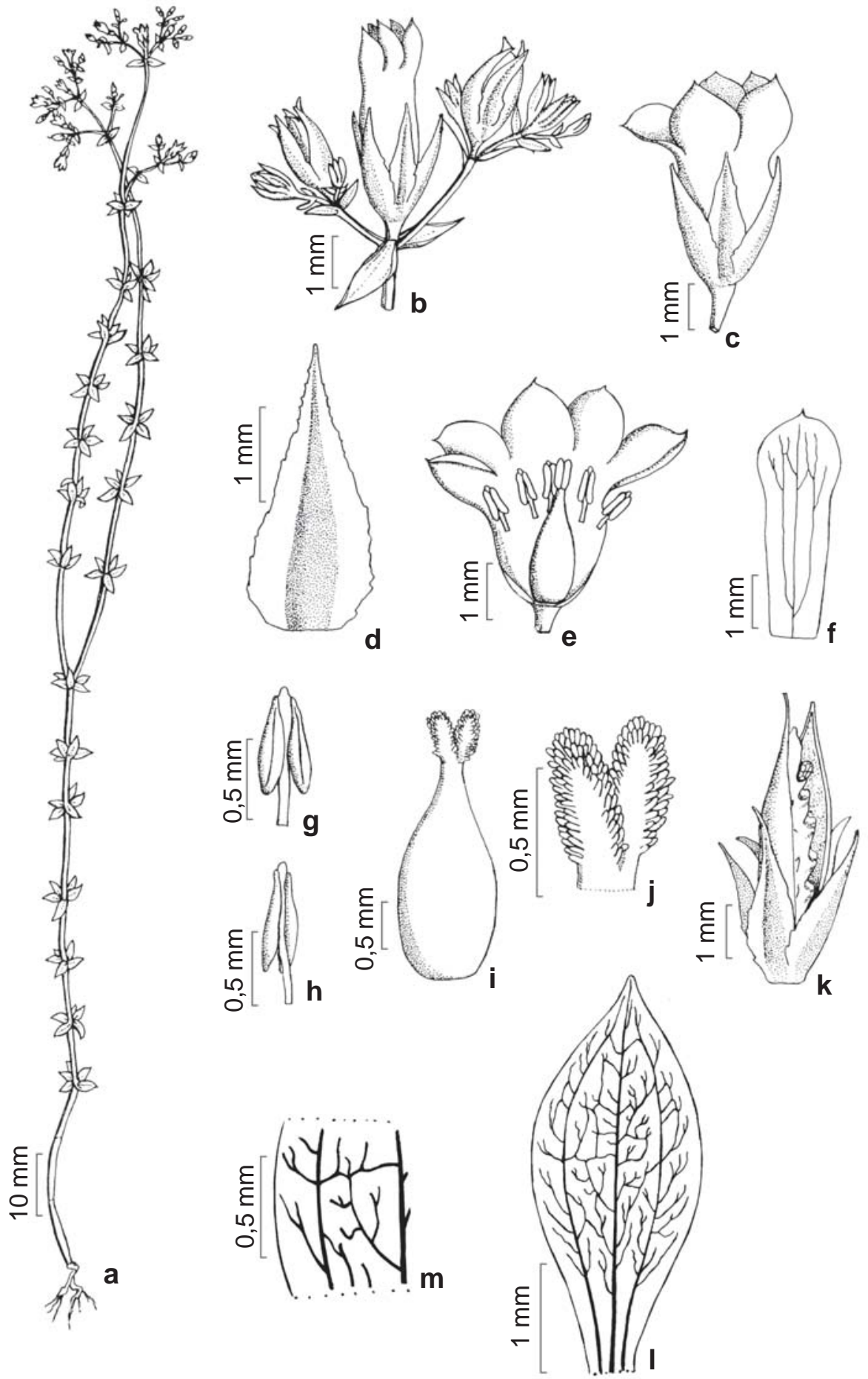

Figura 3 - Curtia conferta (Mart.) Knobl. - a. hábito; b. inflorescência; c. flor; d. sépala; e. flor em seção longitudinal; f.pétala; g. estame, vista ventral; h. estame, vista dorsal; i: gineceu; j. estigma; k. fruto em deiscência; l. folha, venação; m. detalhe da rede de venação. (Smith \& Klein 10732a, F)

Figure 3 - Curtia conferta (Mart.) Knobl. - a. habit; b. inflorescence; c. flower; d. sepal; e. flower, longitudinal section; f. petal; g. stamen, ventral view; h. stamen, dorsal view; i: gynoecium; j. stigma; k. dehiscence fruit l. leaf, venation; m. detail of the venation system. (Smith \& Klein 10732a, F) 
ou ovadas (lanceoladas ou estreito-ovadas), ápice agudo ou acuminado; profilos $0,3-2 \times$ 0,2-1 mm. Flores 3-5 mm, homostílicas; pedicelo 0,5-1,7 mm compr. Sépalas 1,7-3 $\times$ 0,8-1,3 mm, lanceoladas ou estreito-ovadas, ápice acuminado, margens denticuladas, alcançando o ápice do tubo corolino ou logo abaixo dele. Corola branca ou amarelada; tubo 2-3 mm compr., reto, glabro, estreitado no ápice, levemente expandido na região mediana; lobos 0,7-1,6 mm compr., ovados, orbiculares ou suborbiculares, com ápice obtuso ou apiculado. Androceu com filetes de 0,2-0,4 $\times$ 0,05-0,08 mm, inseridos na região mediana do tubo corolino ou levemente acima; anteras 0,50,7 mm compr., introrsas, conectivo das anteras prolongado 40-90 $\mathrm{mm}$ acima das tecas, inteiro. Gineceu 2,1-3 mm compr.; ovário oblongo ou ovado; estigma 0,4-0,6 mm compr., oblongo ou linear; papilas estigmáticas 40-70 ×20-30 mm, oblongas ou lineares. Cápsulas 4-5,4 mm compr., oblongas.

Material examinado: BRASIL. MINAS GERAIS: Poços de Caldas, s.d., fl. e fr., A. Regnell et al. 897 (C, US); Santana do Riacho, rodovia Belo Horizonte - Conceição do Mato Dentro, 3.III.1981, fl. e fr., $M$. C. Amaral et al. CFSC 7166 (UEC); PARANÁ: Guaratuba, Serra de Araçatuba, 10.XI.1959, fl. e fr., G. Hatschbach 5559 (US); São José dos Pinhais, 24.II.1976, fl. e fr., G. Hatschbach 38870 (SPF); Tijucas do Sul, 14.I.1978, fl. e fr., R. Kummrow 1224 (C); Três Barras do Paraná, 25.I.1916, fl. e fr., P. Dusén 17521 (BM, F); RIO GRANDE DO SUL: Osório, fazenda Arroio, 23.I.1958, fl. e fr., B. Rambo 63587 (B); SANTA CATARINA: Campo Alegre, Morro do Iquererim, 10.I.1958, fl. e fr., R. Reitz \& R. M. Klein 6114 (US); Garuva, Monte Crista, 19.I.1961, fl. e fr., R. Reitz \& R. M. Klein 10655 (L, US); Laguna, Iannam, 1889, fl. e fr., E. Ule 1088 (US); Mafra, estrada Tingui para Mafra, 2.II.1957, fl. e fr., L. B. Smith \& R. M. Klein 10617 (NY, R); Porto União, fazenda Frei Gregório, 4.II.1957, fl. e fr., L. B. Smith \& R. M. Klein 10732 (F, US); ibid., 6.I.1962, fl. e fr., R. Reitz \& R. M. Klein 11590 (NY); ibid., Serra da Taquara Verde, 15.III.1957, fl. e fr., L. B. Smith \& R. M. Klein 12161 (US); São José, Serra da Boa Vista, 24.I.1961, fl. e fr., R. Reitz \& R. M. Klein 10704 (US); SÃO PAULO: Batatais, s.d., fr., P. Lund s.n. (C 142/98-3); Franca, s.d., fl. e fr., L. Riedel s.n. (BR 2887/79-1); Itararé, fazenda Espinho, 22.V.1993, fl. e fr., V. C. Souza et al. 3843 (SP); sem localidade, s.d., fl. e fr., A. F. M. Glaziou 8175 (C).

Martius (1827) apresenta uma ilustração onde os filetes são longos e inseridos próximo à base do tubo corolino, mas descreve os estames como curtos e inseridos próximo ao ápice do tubo. A análise dos materiais mostrou que os filetes são relativamente curtos e estão inseridos na metade superior do tubo corolino até próximo à região mediana. Martius (1827) também descreve as sépalas como finamente pubescentes no dorso, mas tal característica não foi observada nos materiais de $C$. conferta examinados. Como o material-tipo citado por Martius (1827) não foi localizado nos herbários consultados, incluindo B, BR e M, foi escolhida a gravura de sua obra como lectótipo.

A espécie ocorre no Brasil, nos estados de MG, PR, RS, SC e SP, em campos rupestres e cerrados, em altitudes de 100 a $1.350 \mathrm{~m}$. Floresce e frutifica de janeiro a junho.

3. Curtia diffusa (Mart.) Cham., Linnaea 8: 14. 1833. Schuebleria diffusa Mart., Nov. Gen. sp. pl. 2: 114; tab. 186, fig. 1. 1827. Tipo: BRASIL. MINAS GERAIS: Serro, Pico do Itambé, IV.1818, fl., C. F. P. Martius s.n. (lectótipo M 2156 n.v., aqui designado fotocópia UEC).

Figs. 2, 4

Schuebleria pusilla Griseb., Gen. sp. Gent.: 163. 1839. Curtia pusilla (Griseb.) Knobl., Bot. Centralbl. 60 (11): 357. 1894. Tipo: BRASIL. MINAS GERAIS: 1818, fl., F. Sellow s.n. (lectótipo L 4815, aqui designado - fotografia UEC), syn. nov.

Ervas, 4-35 cm alt.; caule 4-6-angulado, 0,3-1,2 mm diâm.; entrenós 8-30 mm compr., maiores que o comprimento das folhas. Folhas 2 ou 3 por nó, 2,5-7,5 ×1,7-5,1 mm, verdes ou vináceas, elípticas (elípticas, amplo-elípticas ou suborbiculares) ou ovadas (estreito-ovadas ou ovadas), ápice agudo ou acuminado, profilos 0,3-1,5×0,2-1 mm. Flores 2,5-4,8 mm compr., homostílicas; pedicelo 0,6-3 mm. Sépalas verdes ou vináceas, $1,8-2,5 \times 0,52-0,8 \mathrm{~mm}$, lanceoladas, ápice acuminado, margem denticulada, alcançando o ápice do tubo corolino ou logo abaixo dele. Corola branca ou 
azulada; tubo 2-3 mm compr., reto, piloso internamente na região mediana, às vezes levemente alargado no ápice e levemente estreitado na base; lobos 0,8-1,5 mm compr., orbiculares ou suborbiculares, ápice obtuso a levemente agudo. Androceu com filetes de $0,3-0,4 \times 0,05-0,09 \mathrm{~mm}$, inseridos na região mediana do tubo corolino ou levemente acima; anteras $0,4-0,8 \mathrm{~mm}$ compr., livres, introrsas, conectivo das anteras prolongado $30-50 \mathrm{~mm}$ acima das tecas, inteiro. Gineceu 1,7-2,7 mm compr.; ovário oblongo ou ovado; estigma 0,4 a $0,6 \mathrm{~mm}$ compr., oblongo ou linear; papilas estigmáticas 40-90× 20-40 mm, oblongas ou lineares. Cápsulas 3,4-4 mm compr., oblongas. Material examinado: BRASIL. MINAS GERAIS: Catas Altas, Serra do Caraça, 22.III.1957, fl. e fr., E. Pereira 2601 (GFJP, RB); Conselheiro Matta, s.d., fl. e fr., A. C. Brade 13621 (RB); Curvelo, Serra do Tigre, 6.IV.1980, fl. e fr., F. Barros 128 (F); Diamantina, estrada para Guinda, 2.II.2002, fl. e fr., L. Meireles et al. 931 (UEC); ibid., Serra do Espinhaço, 12 km sudoeste de Diamantina, 18.I.1969, fl. efr., H. S. Irwin et al. s.n. (UB); Gouveia, 14.IV.1987, fl. e fr., N. Menezes et al. CFCR 10463 (UEC); Grão Mogol, 13.IV.1981, fl. e fr., I. Cordeiro et al. CFCR 825 (SP); Jaboticatubas, 14.II.1973, fl. e fr., G. Hatschbach 31566 (US); Ouro Preto, Pico do Itacolomi, IV. 1818, C. F. P. Martius s.n. (BR n.v. fotocópia UEC), 24.II.1884, fl. e fr., A. F. M. Glaziou 15244 (BR, C, R); Pedra Azul, 3.II.1965, fl. e fr., A. Duarte 9030 (HB, RB); Santa Luzia, 18.II.1972, fl. e fr., W. Anderson et al. 36218 (NY, UB); Santana do Riacho, Serra do Cipó, 22.III.1982, fl. e fr., J. R. Pirani et al. CFSC 8046 (UEC); ibid., Alto do Palácio, 27.I.1986, fl. e fr., I. Cordeiro et al. CFSC 9572 (UEC); ibid., Retiro do Barbado, 22.IV.1982, fl. e fr., M. C. Amaral et al. CFSC 8418 (UEC); Santo Antônio do Itambé, Pico do Itambé, 12.II.1972, fl. e fr., W. Anderson et al. s.n. (UB); São João da Chapada, subida do pico São João, 24.III.1970, fl. e fr., H. S. Irwin et al. 28300 (NY, UB); Serra do Rio Grande, 4.V.1931, fl. e fr., Y. Mexia 5750 (BM, F, G, M, NY, R, VIC); Serro, fazenda Bocaina, 4.III.1999, fl. e fr., $F$. Feres \& S. Crespo 99/45 (UEC); Trinta Réis, estrada para Diamantina, 27.I.1986, fl. e fr., I. Cordeiro et al. 9229 (SPF).

Os síntipos de $C$. diffusa são duas coleções de Martius, de Minas Gerais, datadas de abril de 1818, provenientes dos Picos do
Itambé (M 2156) e do Itacolomi (BR). Com base na análise das fotocópias desses materiais, o exemplar do Pico do Itambé, depositado no herbário de Munique, foi escolhido como lectótipo por apresentar flores com o tubo corolino nitidamente reto, sem estreitamento no ápice, característica importante na delimitação da espécie e na sua separação de C. conferta.

Grisebach (1845) diferenciou Schuebleria diffusa de S. pusilla apenas pelo conectivo das anteras, considerado pelo autor apiculado em S. pusilla e não apiculado em S. diffusa. Progel (1865) cita as duas espécies na Flora brasiliensis e as considera próximas, diferenciando-as pela presença de tricomas no tubo corolino internamente em S. diffusa e ausência de tricomas em $S$. pusilla. O holótipo S. pusilla não foi localizado e a análise do isótipo, aqui eleito como lectótipo deste nome, confirmou sua sinonimização em $C$. diffusa, onde destacase o tubo corolino piloso internamente.

A espécie ocorre em Minas Gerais, nos campos rupestres e cerrados da Cadeia do Espinhaço, em altitudes de 1.200 a $1.550 \mathrm{~m}$. Floresce e frutifica de janeiro a maio.

4. Curtia obtusifolia (Spruce ex Benth.) Knobl., Bot. Centralbl. 60(11): 357. 1894. Schuebleria obtusifolia Spruce ex Benth., J. Bot. (Hooker) 6: 194. 1854. Tipo: BRASIL. AMAZONAS: São Gabriel da Cachoeira, 1.IV.1852 , fl. e fr., R. Spruce 2011 (holótipo K; isótipos BM, B, C, F, G, NY, RB fotografia UEC).

Figs. 1,5

Ervas, 8,5-40 cm alt.; caule 4-angulado, 0,6-2 mm diâm.; entrenós 1-3 cm compr. Folhas 2 por nó, $7-11 \times 3-8,5 \mathrm{~mm}$, ovadas (amplo-ovadas, ovadas, estreito-ovadas ou lanceoladas), ápice obtuso ou agudo; profilos 0,8-7×0,3-5,3 cm. Flores 2,2-4,7 mm compr., distílicas; pedicelo 0,6-2,5 mm compr. Sépalas 2,2-3 × 0,5-0,8 mm, lanceoladas, ápice acuminado, margens aproximadamente inteiras a levemente denticuladas, quase alcançando o ápice do tubo corolino ou, mais raramente, 
ultrapassando-o levemente. Corola branca; tubo 2-3,5 mm compr., reto, glabro, frequentemente levemente estreitado na base e levemente expandido na região mediana; lobos 0,5-0,9 mm compr., ovados ou suborbiculares, ápice obtuso. Androceu com conectivo das anteras não pronunciado acima das tecas; em espécimes longistilos, filetes $0,2-0,6 \times 0,05-0,07 \mathrm{~mm}$, inseridos na região mediana do tubo corolino ou levemente abaixo; anteras 0,4-0,7 mm compr., conatas, extrorsas; em espécimes brevistilos, filetes $0,3-0,5 \times 0,05-0,07 \mathrm{~mm}$, inseridos na região mediana do tubo ou levemente acima; anteras 0,4-0,6 mm compr., livres na flor desenvolvida e levemente conatas ou coniventes na flor em botão, introrsas. Gineceu com ovário oblongo ou ovado; em espécimes longistilos, gineceu 1,6-3,5 mm compr., estigma 0,3-0,5 mm compr., oblongo ou linear, papilas estigmáticas 80-200 × 12-20 mm, lineares; em espécimes brevistilos, gineceu, até 1,4 mm compr., estigma 0,15-0,2 mm compr., oblongo ou subgloboso, papilas estigmáticas $10-25 \times 7,5-20 \mathrm{~mm}$, oblongas ou subglobosas. Cápsulas 2,5-4,3 mm compr., oblongas.

Material examinado: BRASIL. AMAZONAS: rio Curicuriary, 20.XI.1936, fl. e fr., A. Duarte s.n. (RB 37602); rio Negro, $5 \mathrm{~km}$ acima da embocadura, 8.XI.1971, fl. e fr., G. T. Prance et al. 16192 (F, M, R, US); rio Purus, 21.X.1971, fl. e fr., G. T. Prance et al. 15500(US). VENEZUELA. TERRITÓRIOFEDERAL AMAZONAS: Caño Pimichin, II.1958, fl. e fr., V. Vareschi 6772 (NY); Cerro Yapacana, 5 km da desembocadura do Caño Cotua com o rio Orinoco, sudoeste do Cerro Yapacana, 30.IV.1970, fr., J. A. Steyermark \& G. Bunting s.n. (US 2589278); Savana El Venado, 23.XI.1953, fl. e fr., B. Maguire et al. 36339 (F, US).

Curtia obtusifolia apresenta distribuição geográfica semelhante à de $C$. quadrifolia e ambas compartilham características que às distinguem das demais espécies de Curtia, tais como: folhas relativamente mais largas, conectivo das anteras não prolongado acima das tecas e ausência de eixo central na cápsula.

A espécie ocorre na região amazônica, no Brasil e na Venezuela, em cerrados, em altitudes de 50 a $300 \mathrm{~m}$. Floresce e frutifica de outubro a abril.
5. Curtia quadrifolia Maguire, Mem. New York Bot. Gard. 32: 352; figs. 72 h-q, 75 a-h. 1981. Tipo: VENEZUELA. TERRITÓRIO FEDERAL AMAZONAS: rio Guainia, 1 km leste de Maroa, 16.V.1953, fl. e fr., B. Maguire \& C. Maguire 35685 (holótipo NY - fotografia UEC; isótipos F, US). $\quad$ Figs. 1,6

Ervas, 14-40 cm alt.; caule 6- ou 8angulado, 0,8-2,9 mm diâm.; entrenós 7-25 mm compr. Folhas (3)4 por nó, 5-11,8×4,5-8,4 mm, elípticas (suborbiculares) ou ovadas (ovadas ou amplo-ovadas), ápice acuminado ou agudo, profilos 0,7-5 ×0,7-4,2 mm. Flores 2,5-3,5 mm compr., homostílicas; pedicelo 0,3-2,3 mm compr. Sépalas 2-3 × 0,5-0,9 mm, lanceoladas, ápice acuminado, margens denticuladas, alcançando logo abaixo do ápice do tubo corolino até, mais frequentemente, ultrapassando o ápice do tubo ou o ápice dos lobos corolinos. Corola branca; tubo 1,9-2,4 mm compr., reto, glabro, levemente estreitado próximo à base e, às vezes, levemente expandido na região mediana; lobos 0,7-0,9 mm compr., ovados ou suborbiculares, ápice obtuso. Androceu com filetes de 0,2-0,3×0,06-0,08 mm, inseridos na região mediana do tubo corolino ou levemente acima dela; anteras 0,3-0,4 mm compr., livres, introrsas, conectivo das anteras não prolongado acima das tecas. Gineceu 1,72,3 mm compr.; ovário oblongo ou subgloboso; estigma 0,1-0,25 mm compr., capitado ou subgloboso; papilas estigmáticas 13-35×10-18 mm, oblongas ou subglobosas. Cápsulas 2,3-3,3 mm compr., oblongas ou ovadas.

Material examinado: BRASIL. AMAZONAS: Coari, lago Coari, s.d., fl., C. F. P. Martius (U 2166 - UEC fotocópia). COLÔMBIA. Bogotá, rio Paranapichuna, VI.1953, fl. e fr., R. E. Schults \& I. Cabrera 19946 (US); Caquetá, rio Caquetá, 17.XII.1976, fl. e fr., C. Sastre \& H. Reichel 4909 (G, US); ibid., 5.VII.1959, fl. e fr., B. Maguire et al. 44134 (NY); Cerro Yapoboda: rio Kuduyari, 3.X.1951, fl. e fr., R. E. Schults \& I. Cabrera 14200 (US). VENEZUELA. TERRITÓRIO FEDERAL AMAZONAS: Maroa, 20.IV.1970, fl. e fr., J. A. Steyermark \& G. Bunting 102828 (F, NY, US); ibid., San Carlos Rio Negro, 20 km da confluência do rio Negro e Brazo Casiquiare, 16.I.1979, fr., H. Clark 6942 (NY); ibid., km 11 na rodovia San CarlosSolano, 17.VII.1980, fl. e fr., O. Huber et al. 5688 


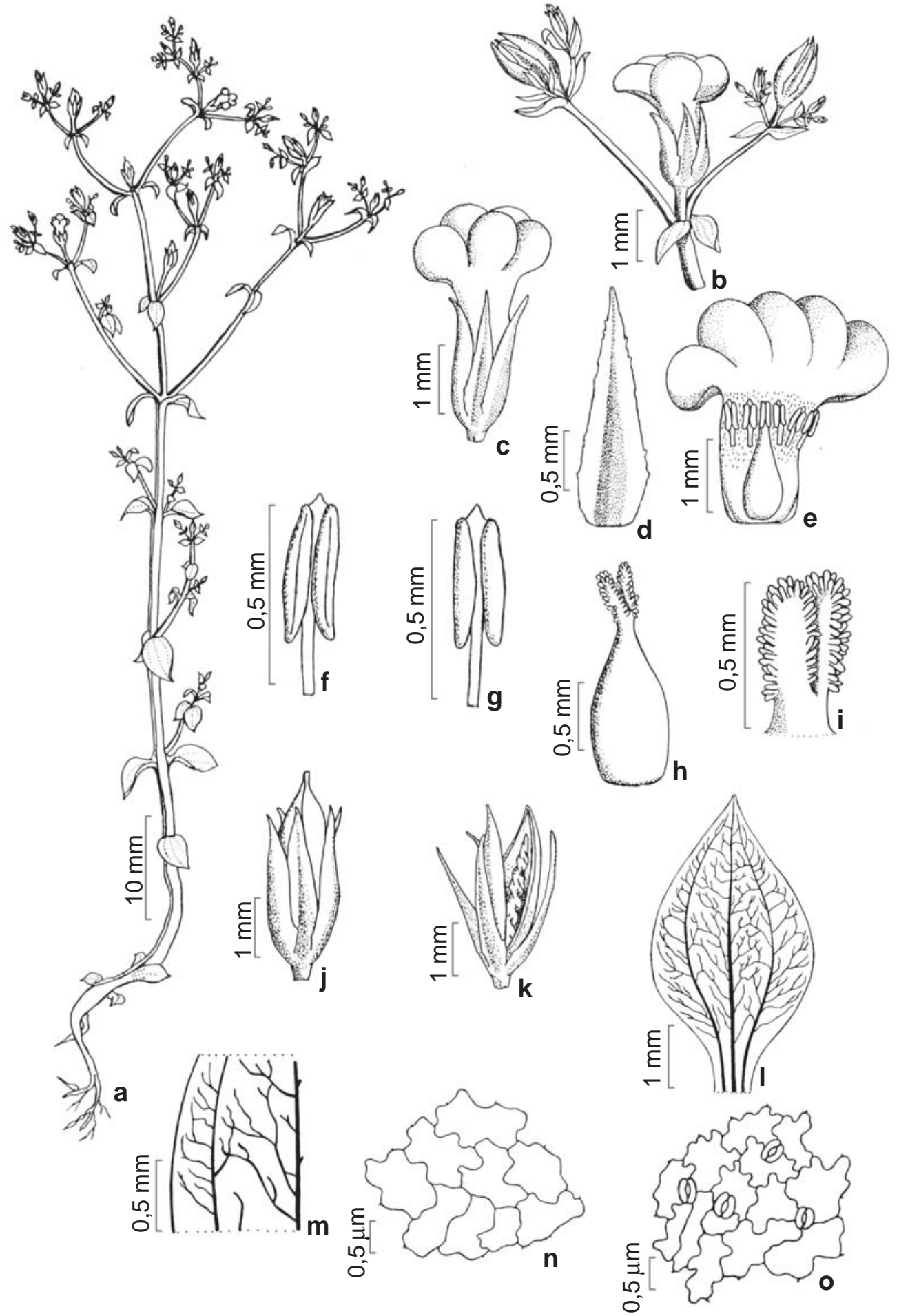

Figura 4 - Curtia diffusa (Mart.) Cham. - a. hábito; b. inflorescência; c. flor; d. sépala; e. flor em seção longitudinal; f. estame, vista ventral; g. estame, vista dorsal; h. gineceu; i. estigma; j. fruto pré-deiscente; k. fruto deiscente; l. folha, venação; m. detalhe da rede de venação; n. epiderme adaxial; o. epiderme abaxial, com estômatos. (Feres \& Crespo 99/45, UEC)

Figure 4 - Curtia diffusa (Mart.) Cham. - a. habit; b. inflorescence; c. flower; d. sepal; e. flower, longitudinal section; f. stamen, ventral view; g. stamen, dorsal view; h. gynoecium; i. stigma; j. pre-dehiscence fruit ; k. dehiscence fruit; l. leaf, venation; m. detail of the venation system; n. adaxial epidermis; o. abaxial epidermis, with stomata. (Feres \& Crespo 99/45, UEC) 
(NY); ibid., savana Hechimoni, rio Siapa, 25.VII.1959, J. Wurdack \& L. Adderley 43626 (RB fotografia UEC).

A espécie destaca-se por apresentar ramos nitidamente arqueados, flores relativamente menores, folhas mais largas e fruto indeiscente a parcialmente deiscente, o qual não apresenta o cálice persistente ao ser liberado dos ramos. Curtia quadrifolia ocorre no Brasil, Colômbia e Venezuela, predominando em cerrados da região amazônica, em altitudes de até cerca de 300 m. Floresce e frutifica o ano todo.

6. Curtia tenella (Mart.) Cham., Linnaea 8: 13. 1833. Schuebleria tenella Mart., Nov. Gen. sp. pl. 2: 118. 1827. Curtia tenuifolia subsp. tenella (Mart.) Grothe \& Maas, Proc. Kon. Ned. Akad. Wetensch., C 87(1): 40. 1984. Tipo: BRASIL. GOIÁS: córrego Ponte Feita, VI.1820, fl. e fr., J. Pohl s.n. (holótipo W n.v. - fotografia UEC).

Figs. 7,8

Ervas, 4,5-36 cm alt.; caule 4-angulado, 0,31,2 mm diâm.; entrenós 10-35 mm compr. Folhas 2 por nó, 2,6-14,5×0,4-3 mm, oblongas (lineares, loradas ou estreito-oblongas), ápice obtuso ou agudo; profilos 0,8-7×0,2-1,8 mm. Flores 3,5$7 \mathrm{~mm}$ compr., homostílicas; pedicelos florais 0,5 $3 \mathrm{~mm}$ compr. Sépalas $2-4 \times 0,6-0,8 \mathrm{~mm}$, lanceoladas, ápice acuminado, margens inteiras ou levemente denticuladas, alcançando o ápice do tubo corolino ou logo abaixo dele. Corola tubulosa, branca, amarela, ou lobos brancos com tubo amarelo; tubo 2,5-4,5 mm compr., reto e levemente estreitado no ápice, frequentemente levemente estreitado na base, piloso na região mediana internamente; lobos 0,8-2 mm compr., obovados, orbiculares ou suborbiculares, ápice obtuso a levemente agudo. Androceu com filetes de 0,3-0,5×0,04-0,07 mm, inseridos logo abaixo da região mediana do tubo corolino ou no seu terço inferior; anteras 0,4-0,6 mm compr., livres, introrsas, conectivo das anteras não prolongado acima das tecas. Gineceu 1,5-2,5 mm compr.; ovário oblongo a ovado; estigma $0,3-0,7 \mathrm{~mm}$ compr., linear ou oblongo; papilas estigmáticas 40-100 × 20-40 mm, lineares ou oblongas. Cápsulas 2,5-5 mm compr., oblongas.
Material examinado: BOLÍVIA. Tipuani, Hacienda Carana, 5.IV.1923, fl. e fr., D. Buchtien 7520 (US). BRASIL. AMAPÁ: Macapá, próximo ao Parque Florestal Fazendinha, 3.VII.1983, fl. e fr., S. Mori et al. 15750 (NY); rio Araguari, 16.VIII.1961, fl. e fr., J. M. Pires et al. 50358 (NY); AMAZONAS: Araçá, margem do rio Araçá próximo à Serrinha, 25.VII.1985, fl. e fr., G. T. Prance et al. 29806 (NY); Manaus, Iarapés Lage, rodovia Caracari Km 13, 9.V.1974, fl. e fr., G. T. Prance et al. 21038 (NY); DISTRITO FEDERAL: Brasília, Catetinho, 8.III.1965, fl. e fr., L. B. Smith A-41 (UB); GOIÁS: Alto Paraíso de Goiás, Parque Nacional Chapada dos Veadeiros, 9.III.1999, fl. e fr., T. Filgueiras s.n. (SP 344711); Cristalina, Serra dos Cristais, 2.III.1966, fl. e fr., H. S. Irwin et al. 13305 (NY); Guará, 19.III.1968, fl. e fr., H. S. Irwin et al. 21476 (NY, UB); Niquelândia, 14.IV.1996, fl. e fr., R. Mendonça et al. 2481 (US); Posse, Rio da Prata, 7.IV.1966, fl. e fr., H.S. Irwin et al. 14518 (NY, UB); São João d’Aliança, Serra Geral do Paraná, 17.III.1971, fl. e fr., H. S. Irwin et al. 32016 (NY, UB, US); MATO GROSSO, Chapada dos Guimarães, Casa de Pedra, IV.1911, fl. e fr., F. C. Hohene 3793 (R); Cuiabá, s.d., fl. e fr., G. O. A. Malme 3103 (R); Nova Xavantina, Serra Azul, 16.VI.1966, fl. e fr., $H$. S. Irwin et al. 17266 (UB); MINAS GERAIS: Diamantina, IV.1918, fl. e fr., F. C. Hoehne s.n. (UEC); Lagoa Santa, s.d., fl. e fr., E. Warming 1118 (C); Santa Luzia, Serra do Cipó, 14.IV.1935, fl. e fr., $M$. Barreto 1245 (F); Santana do Riacho, 30.III.1980, fl. e fr., I. Cordeiro et al. 6080 (UEC); Serra do Cabral, 9.III.1970, fl. e fr., H. S. Irwin et al. 27222 (F, RB, UB); PARÁ: Almerim, 21.IV.1923, fl. e fr., A. Duarte 18561 (RB); Ilha de Marajó, Salvaterra, 1415.IX.1976, fl. e fr., N. Carmo et al. s.n. (NY); Santarém, VI.1850, fl. e fr., R. Spruce s.n. (C 142/9823, M8113); Vigia, Campo do Caembé, 10.VIII.1954, fl. e fr., G. A. Black 54-16772 (IAN); SERGIPE: Itabaiana, 13.IX.1981, fl. e fr., Andrade-Lima et al. 81-18(IPA). COLÔMBIA. Los Llanos, rio Casanare, 19-20.X.1938, fl. e fr., J. Cuatrecasas 3854 (US); Meta, Serra La Macarena, 6.II.1950, fl. e fr., W. Phillipson 2404 (BM). COSTA RICA. Alajuela, San Pedro de Poas, 5.XI.1933, fl. e fr., A. M. Brenes 17360 (NY); San Mateo, 4.X.1922, fl. e fr., A. M. Brenes 3670 (F); San Pedro de la Calabaza, X.1896, fl. e fr., H. Pittier \& Tonduz s.n. (L 2887/79-21). GUIANA FRANCESA. Savana Aubanéle, 9.VI.1986, fl. e fr., G. Cremers \& H. Cremers 10712 (US); Savana Onemark, 18.V.1990, fl. e fr., G. Cremers \& M. Hoff 11450 (B, US). HONDURAS. El Cayo, Augustine Montain, 5.XI.1959, fl. e fr., D. Hunt 201 (US); 


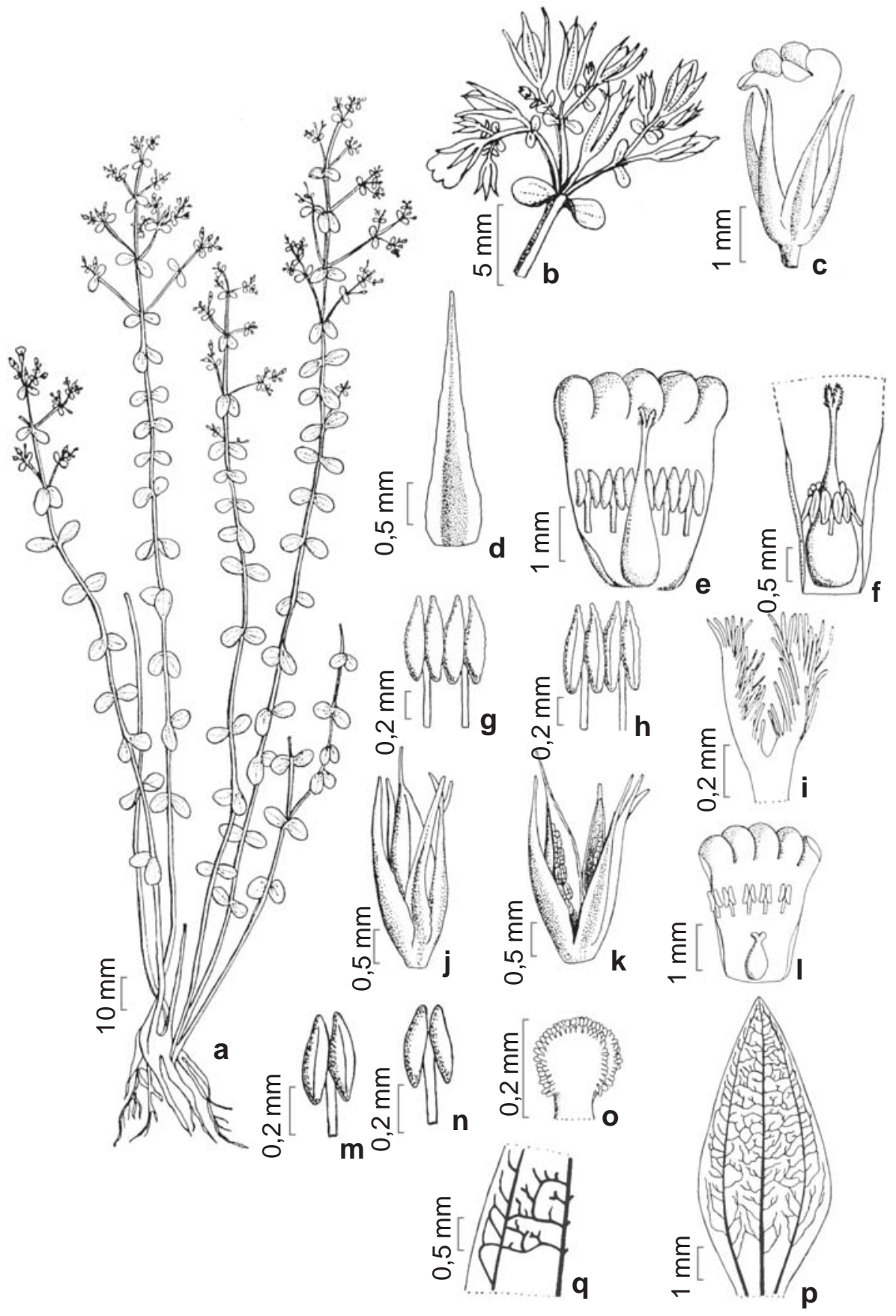

Figura 5 - Curtia obtusifolia (Spruce ex Benth.) Knobl. - a-k. flores longistilas - a. hábito; b. inflorescência; c. flor; d. sépala; e. flor em seção longitudinal; f. parte da corola aberta, mostrando anteras conatas; g. estames, vista ventral; h. estames, vista dorsal; i. estigma; j. fruto pré-deiscente; k. fruto deiscente. l-o. flores brevistilas - l. flor em seção longitudinal; m. estame, vista ventral; n. estame, vista dorsal; o. estigma. p-q. folha: p. folha, venação; q. detalhe da rede de venação. (a-k Spruce 2011, BR; l-o Maguire 36339, US; p-q Duarte, RB 37602)

Figure 5 - Curtia obtusifolia (Spruce ex Benth.) Knobl. - a-k. long-styled flowers - a. habit; b. inflorescence; c. flower; d. sepal; e. flower, longitudinal section; f. part of the corolla is opened, showing connate anthers; g. stamens, ventral view; h. stamens, dorsal view; i. stigma; j. pre-dehiscence fruit; k. dehiscence fruit. l-o. short-styled flowers - l. flower, longitudinal section; m. stamen, ventral view; n. stamen, dorsal view; o. stigma. p-q. leaf: p. leaf, venation; q. detail of the venation system. (a-k Spruce 2011, BR; l-o Maguire 36339, US; p-q Duarte, RB 37602) 
Gracias a Dios, Dursuna, 3.II.1981, fl. e fr., G. Proctor 38869 (BM). PANAMÁ. Cerro Campana, encosta sudeste, 10.XII.1967, fl. e fr., W. Lewis et al. 3092 (F); Coclé, próximo à Olá, 7-9.XII.1911, fl. e fr., $H$. Pittier 5039 (US); Ilha San José, Arquipélago Pearl, 18.IX.1945, fl. e fr., J. Harlow 62 (US); Monte Ancóm, Canal, 2, 6.XII.1923, fl. e fr., P. C. Standley 25218(US); SURINAME. Savana Lobin, VIII.1958, fl. e fr., J. Donselaar \& W. van Donselar 413 (NY). VENEZUELA. BOLÍVAR: Serra Pacaraima, 31.I.1928, fl. e fr., H. Pittier 12788 (US); ibid., Gran Sabana, 3.X.1944, fl. e fr., J. A. Steyermark 59202 (F, US).

Grothe \& Maas (1984), com base no tamanho das sementes e morfologia das células da testa, posicionaram $C$. tenella como subespécie de $C$. tenuifolia. Crespo (2003) mostrou que esses caracteres realmente não permitem separar claramente C. tenuifolia, $C$. tenella e $C$. diffusa. No presente estudo, no entanto, foi constatado que essas espécies são nitidamente distintas com base em caracteres florais. Curtia tenella caracteriza-se pelo conectivo das anteras não prolongado acima das tecas e corola com tubo reto, frequentemente estreitado na base. Em C. tenuifolia, o conectivo é nitidamente prolongado acima das tecas e a corola é infundibuliforme. Características polínicas também confirmaram que $C$. tenella deve ser tratada com uma espécie independente. Crespo \& Marcondes-Ferreira (2006) relataram que a exina é reticulada em $C$. tenella, enquanto, em $C$. tenuifolia, ela é reticulado-espinulosa nas formas brevistilas e mesostilas e reticulada em formas longistilas.

Ocorre no Brasil, nas Regiões Norte, Nordeste, Centro-Oeste e Sudeste, também na Bolívia, Colômbia, Costa Rica, Guiana Francesa, Honduras, Panamá, Suriname e Venezuela, em cerrados e campos rupestres, em altitudes de 80 a 1.600 m. Floresce e frutifica o ano todo.

7. Curtia tenuifolia (Aubl.) Knobl., Bot. Centralbl. 60(11): 357. 1894. Exacum tenuifolium Aubl., Hist. Pl. Guiane 1: 70; tab. 26, fig. 2. 1775. Apophragma tenuifolium
(Aubl.) Griseb., Gen. Sp. Gent.: 163. 1839. Schuebleria tenuifolia (Aubl.) G. Don, Gen. Syst. 4: 202. 1839. Tipo: GUIANA FRANCESA. J. B. C. Aublet sn. (lectótipo Hist. Pl. Guiane 1: tab. 26, fig. 2, aqui designado).

Figs. 9, 10

Schuebleria patula Mart., Nov. Gen. sp. pl. 2: 117; f. 188. 1827. Curtia patula (Mart.) Knobl., Bot. Centralbl. 60(11): 357. 1894. Tipo: BRASIL. MINAS GERAIS: Serro, Pico do Itambé, IV.1818, fl., C. F. P. Martius s.n. (lectótipo M 2162 n.v., aqui designado fotocópia UEC; isolectótipo BR 2887/79-26 n.v. - fotocópia UEC).

Schuebleria coarctata Benth., Ann. Nat. Hist. 2(2): 442. 1839. Tipo: GUIANA: Savana Rupununy, V.1837 , fl. e fr., R. Schomburgk 167 (isótipos BM, G - fotografia UEC), Syn. nov.

Schuebleria patula var. martiana Progel in Mart., Fl. bras. 6(1): 217. 1865. Tipo: BRASIL. GOIÁS: VI.1840, fl. e fr., $G$. Gardner 4280 (lectótipo: BM, aqui designado - fotografia UEC; isolectótipos: F, G, NY).

Schuebleria patula var. selloana Progel in Mart., Fl. bras. 6(1): 217. 1865. Tipo: BRASIL. PARANÁ: Castro, 1826, fl. e fr., $L$. Riedel 367 (lectótipo BR, aqui designado fotografia UEC).

Schuebleria intermedia Progel in Mart., Fl. bras. 6(1): 218, tab. 60, fig. 2. 1865. Curtia intermedia (Progel) Knobl., Bot. Centralbl. 60(11): 357. 1894. Tipo: BRASIL. SÃO PAULO: Mogi das Cruzes, XII.1825, fl., L. Riedel s.n. (lectótipo BR 2887/79-28 n.v., aqui designado - fotocópia UEC; isolectótipo BR 2887/79-16 n.v. - fotocópia UEC), syn. nov.

Schuebleria tenuifolia var. gracilis Progel in Mart., Fl. bras. 6(1): 218. 1865. Tipo: VENEZUELA. Esmeralda, rio Orinoco, XII1853, fl. e fr., R. Spruce 3242 (lectótipo RB, aqui designado - fotografia UEC; isolectótipos BM, G, NY, BR), syn. nov.

Curtia malmeana Gilg, Bot. Jahrb. Syst. 25(60): 42. 1898. Tipo: BRASIL. RIO GRANDE DO SUL: Rio Grande, V.1893, G. O. A. Malme $424 b$ (holótipo S - fotografia UEC), syn. nov. 
Curtia tenuifolia var. tenerrima Malme, Bih. Kongl. Svenska Vetensk. Akad. Handl. 1: 19. 1898. Curtia tenella f. tenerrima (Malme) Malme, Ark. Bot. 3(12): 6. 1904. Tipo: BRASIL. MATO GROSSO: Cuiabá, 3.V.1894, fl., G. O. A. Malme 1602 (holótipo $\mathrm{S}$ - fotografia UEC), syn. nov.

Curtia montevidensis Arech., Anales Mus. Nac. Montevideo, Ser. 2(1): 66; fig. 3. 1910. Tipo: URUGUAI: Carrasco, 1910, J. Arechavaleta s.n. (lectótipo Anales Mus. Nac. Montevideo, Ser. 2(1): fig. 3, aqui designado), syn. nov.

Ervas 6-60 cm alt.; caule 4(6)-angulado, 0,5-2 mm diâm.; entrenós 7-31 mm compr. Folhas 2(3) por nó, 3,5-17 × 0,5-2,1 mm, verdes, vináceas ou roxas, oblongas (lineares, loradas ou estreito-oblongas), ápice obtuso ou agudo; profilos 0,3-6×0,1-0,9 mm. Flores 5,5$17 \mathrm{~mm}$ compr., tristílicas; pedicelo 1-6 mm compr., verde, vináceo ou roxo. Sépalas 3-8,3 $\times 0,8-1,4 \mathrm{~mm}$, verdes ou vináceas, lanceoladas, ápice acuminado, margens inteiras a levemente denticuladas, alcançando desde abaixo da região mediana do tubo corolino até cerca do seu ápice. Corola tubulosa, infundibuliforme, rosa, lilás, púrpura, amarela ou, às vezes, com tubo branco ou amarelo e lobos lilás ou róseos; tubo 4-9 mm compr., piloso internamente na região mediana; lobos 1,4-7 mm compr., ovados, obovados, orbiculares ou suborbiculares, ápice acuminado, agudo, obtuso ou emarginado. Androceu, em espécimes longistilos, com filetes de $0,4-1,2 \times 0,10-0,15$ $\mathrm{mm}$, inseridos próximo à região mediana do tubo corolino ou abaixo dela, no terço inferior do tubo; anteras 0,6-1,5 mm compr., conatas, extrorsas, conectivo prolongado $140-200 \mathrm{~mm}$ acima das tecas, fracamente 2-3-lobado ou inteiro; em espécimes brevistilos e mesostilos, filetes $0,7-1,6 \times 0,07-0,11 \mathrm{~mm}$ e $0,6-1,5 \times$ 0,07-0,09 mm, respectivamente, inseridos próximo à região mediana do tubo corolino ou acima dela, no terço superior do tubo, anteras $0,7-1,3 \mathrm{~mm}$ e $0,6-1,4 \mathrm{~mm}$ compr., respectivamente, livres na flor desenvolvida, levemente conatas ou coniventes na flor em botão, introrsas, conectivo prolongado 60-130 $\mathrm{mm}$ acima das tecas, inteiro. Gineceu com ovário oblongo ou ovado; em espécimes longistilos, gineceu 4-7 mm compr., estigma 0,8-1,8 mm compr., oblongo ou linear, papilas estigmáticas 260-640 × 30-55 mm, lineares; em espécimes brevistilos, gineceu 3-4 mm compr., estigma 0,6-1 mm compr., oblongo, papilas estigmáticas 30-100 × 14-22 mm, lineares ou oblongas; em espécimes mesostilos, gineceu 3-5 mm compr., estigma $0,7-1 \mathrm{~mm}$ compr., oblongo ou linear, papilas estigmáticas 100-185 × 15-25 mm, lineares. Cápsulas 5$11 \mathrm{~mm}$ compr., oblongas.

Material examinado: ARGENTINA. Corrientes, Concepción, 31.XII.1982, fl. e fr., T. Pedersen 13476 (C, G). BRASIL. ACRE: Rio Branco, X.1909, fl. e fr., E. Ule 7652 (B, L); AMAPÁ: Oiapoque, 6.IV.1960, fl. e fr., M. A. Egler 1446 (NY); AMAZONAS: Humaitá, 21.II.1980, fl. e fr., A. Janssen 208 (M, SPF); Iranduba, Campo Amélia, fazenda Belo Horizonte, 20.IV.1986, fl. e fr., G. T. Prance et al. 29993 (F, US); rio Aripuanã, 13.VI.1974, fl. e fr., M. R. Cordeiro 28 (IAN); BAHIA: Abaíra, Catolés, Serra do Porco Gordo, 25.IV.1992, fl. e fr., W. Ganev 199 (HUEFS, UEC); Correntina, fazenda Jatobá, 8.VIII.1992, fl. e fr., M. Aparecida et al. 1584 (UB); Gentio do Ouro, Serra do Assuruá, 27.XI.1992, fl., e fr., M. M. Arbor et al. 5336 (SPF); Mucugê, alto do Morro do Pina, 20.VII.1981, fl. e fr., A. M. Giulietti et al. 1509 (SPF); Rio de Contas, próximo ao Pico das Almas, 21.II.1987, fl. e fr., R. Harley et al. 24611 (UEC); DISTRITO FEDERAL: Brasília, Chapada da Contagem, 19.IV.1979, fl. e fr., G. S. Koury 10 (SP); GOIÁS: Alto Paraíso de Goiás, 22.III.1971, fl. e fr., H. S. Irwin et al. 32945 (BM, F, HB, NY); Caiaponia, rodovia Caiaponia-Aragarças Km 75, 22.VI.1966, fl. e fr., D. R. Hunt \& J. F. Ramos 6141 (NY, RB); Chapada dos Veadeiros, 12.V.2001, fl. e fr., M. Morais 652 (UEC); Niquelândia, 2 km da fazenda Santa Luzia, 6.VIII.1992, fl. e fr., B. Walter et al.s.n. (RB 331733); Pirenópolis, Cocalzinho, 24.IV.1994, fl. e fr., S. Splett 208 (UB); Planaltina, 17.IV.1985, fl. e fr., S. P. Almeida 994 (UB); Serra dos Cristais, 2.III.1966, fl. e fr., H. S. Irwin et al. 13315 (NY); ibid, 4.IV.1973, fl., fr., W. Anderson 8125 (UB); MARANHÃO: Carolina, Serra da Malícia, 27.V.1950, fl. e fr., J. Pires \& G. Black 23337 (US); MATO GROSSO: Chapada dos 


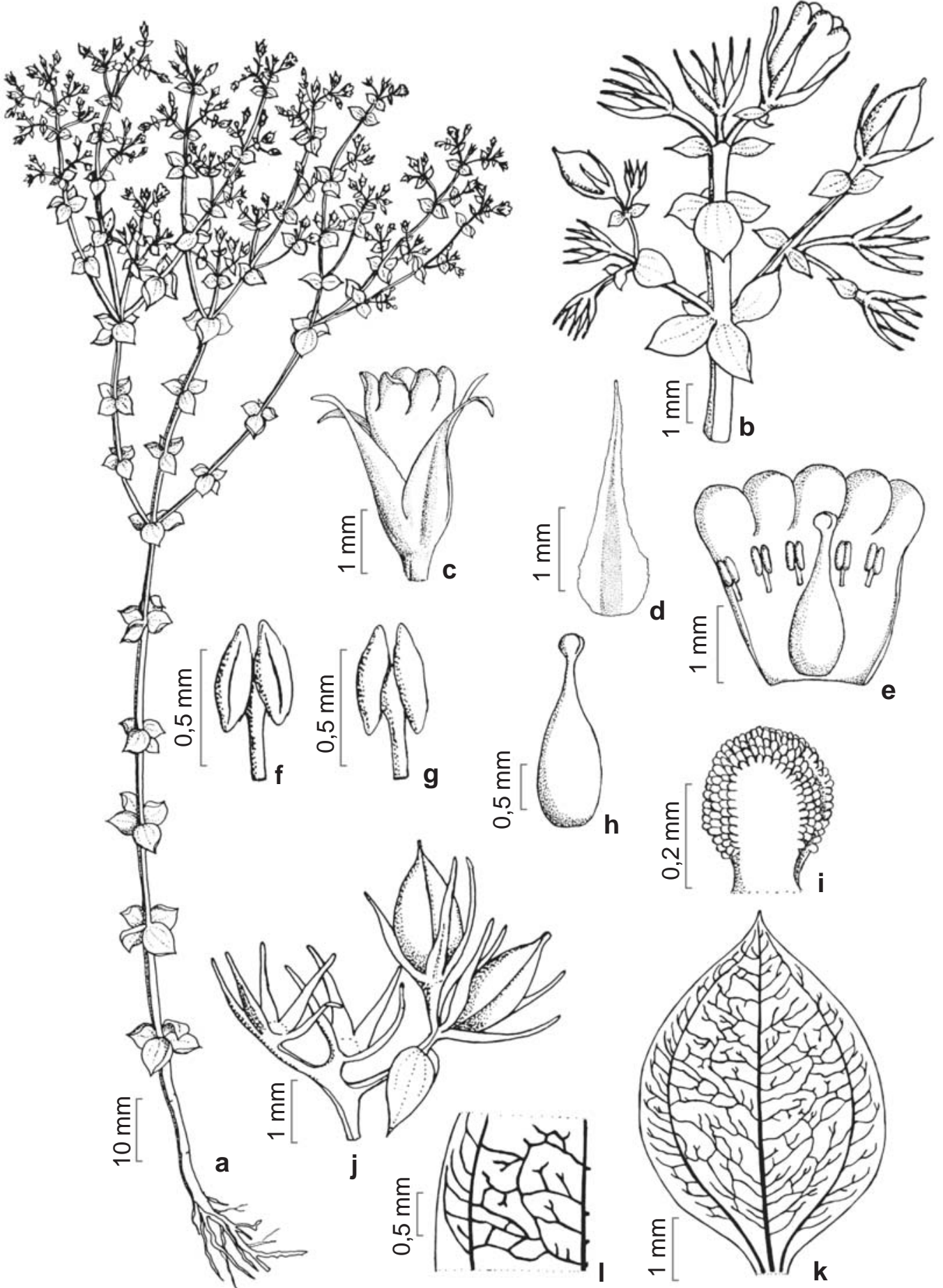

Figura 6 - Curtia quadrifolia Maguire - a. hábito; b. inflorescência; c. flor; d. sépala; e. flor em seção longitudinal; f. estame, vista ventral; g. estame, vista dorsal; h. gineceu; i. estigma; j. frutos ainda presos aos ramos; k. folha, venação; $l$. detalhe da rede de venação. (Wurdack \& Adderley 43626c, RB)

Figure 6 - Curtia quadrifolia Maguire - a. habit; b. inflorescence; c. flower; d. sepal; e. flower, longitudinal section; f. stamen, ventral view; g. stamen, dorsal view; h. gynoecium; i. stigma; j. fruits still connected to branchs; k. leaf, venation; l. detail of the venation system. (Wurdack \& Adderley 43626c, RB) 
Guimarães, Assentado, 10.V.1983, fl. e fr., J. Barcia et al. s.n. (R 193744); Diamantino, entre Diamantino e Cabeça do Lobo, IV.1918, fl. e fr., $J$. G. Kuhlmann 2238 (R); rio Araguaia, drenagem superior, 19.VI.1966, fl.e fr., H. S. Irwin et al. 17433 (F, IAN, NY, RB, UB); rio Tuatuari, margem direita, próximo ao porto indígena Capitão Vasconcelos, 15.V.1958, fl. e fr., A. Lima 58-3170 (IPA, RB); Serra da Chapada, s.d., fl. e fr., G. O. A. Malme 3343 (C, R, US); Serra do Roncador, 86 km N de Xavantina, 31.V.1966, fl. e fr., H. S. Irwin et al. s.n. (UB 25483); Vila Bela da Santíssima Trindade, 13.VII.1985, fl. e fr., A. Souza et al. 1301 (R). MATO GROSSO DO SUL: Maracaju, fazenda Santo Antônio, 29.XII.1973, fl. e fr., D. Sucre 10565 (RB); MINAS GERAIS: Araxá, Serra da Canastra, 3.IV.1999, fl. e fr., F. Feres et al. 99/65 (UEC); Buenópolis, Serra do Cabral, VIII.1998, fl. e fr., P. Seda s.n. (UEC 114289); Congonhas do Norte, Serra da Carapina, 3.III.1998, fl. e fr., A. Rapini et al. 569 (UEC); Conselheiro Matta, VI.1934, fl. e fr., A. C. Brade 13618 (RB); Couto Magalhães, estrada em direção a Mendanha, 5.VI.1967, fl. e fr., A. P. Duarte 10458 (RB); Diamantina, s.d., fl. e fr., A. F. M. Glaziou 1880 (US); ibid., São João da Chapada, Serra do Espinhaço, 26.III.1970, fl. e fr., H. S. Irwin et al. 28404 (UB); ibid., 5 km ao norte de São João da Chapada, 28.III.1970, fl. e fr., H. S. Irwin et al. 28523 (NY); Gouveia, Serra do Barro Preto, 9.IV.1982, fl. e fr., A. Furlan et al. CFCR 3205 (UEC); Grão Mogol, fazenda Bocaina, 4.III.1999, fl. e fr., F. Feres et al. 99/44 (UEC); ibid., Serra do Grão Mogol, 27.V.1988, fl. e fr., D. C. Zappi et al. 12003 (UEC); Itabirito, Pico do Itabirito, 25.IV.1994 (fl., fr.), W. A. Teixeira s.n. (BHCB 28500 ); Jaboticatubas, caminho para Capão dos Palmitos, 31.V.1991, fl. e fr., R. Simão-Bianchini \& S. Bianchini 12736 (UEC); João Pinheiro, 28.VII.1961, fl. e fr., E. P. Heringer 8536/730 (HB, NY, UB, US,); Joaquim Felício, estrada para Serra do Cabral, 17.IV.1981, fl. e fr., L. Rossi et al. 1094 (SPF); Lagoa Santa, s.d., fl. e fr., Engler 1117 (C); Ouro Preto, Pico do Itacolomi, 24.IV.1942, fl. e fr., M. Magualhães 2085 (IAN); Poços de Caldas, Morro do Ferro, 27.IV.1968, fl. e fr., A. Lima 122-68 (IPA); Santa Luzia, Serra do Cipó, 15.IV.1935, fl. e fr., M. Barreto 1246 (R); Santana do Riacho, 30.III.1980, fl. e fr., I. Cordeiro et al. 6072 (UEC); ibid., Alto do Palácio, 4.III.1991, fl. e fr., J. R. Pirani et al. 11902 (UEC); São Roque de Minas, Parque Nacional Serra da Canastra,
15.III.1990, fl. e fr., H. C. Souza (n. n.v.) (BHCB); São Sebastião do Paraíso, estrada em direção à Baú, 10.IV.1945, fl. e fr., A. C. Brade \& A. Barbosa 17686 (RB); Serra do Cabral, Morro do Jucão, VII.1985, fl. e fr., M. G. L. Wanderley et al. 829 (UEC); Serra do Espinhaço, 11.III.1973, fl. e fr., $W$. P. Anderson 8621 (NY, UB); Serro, fazenda Bocaina, 4.III.1999, fl. e fr., F. Feres \& S. Crespo 99/44 (UEC); Uberlândia, Estação Ecológica do Panga, 10.XII.1993, fl. e fr., $R$. Romero \& A. A. Arantes 586 (UEC); PARÁ: Cachimbo, 16.21.V.1955, fl. e fr., W. Bockermann 182 (IAN); Belém, 6.IV.1951, fl. e fr., G. A. Black \& M. Magalhães 51-12141 (IAN); Ilha de Marajó, 1977, fl. e fr., J. Schwacke 138 (R); Itapuã, 10.VI.1976, fl. e fr., P. R. P. Bouças \& J. Medeiros 103 (IAN); Muaná, rio Atuá, 23.X.1970, fl e fr., E. Oliveira 5308 (IAN); Tucuruí, margem direita do rio Tocantins, 28.V.1980, fl. e fr., M. G. Silva \& C. S. Rosário 5208 (NY); PARANÁ: Guarapuava, 16.II.1949, fl. e fr., A. C. Brade 19632 (RB); Lagoa Dourada, 15.IV.1909, fl. e fr., P. Dusén 8003 (BM, G); Ponta Grossa, 14.II.1949, fl. e fr., A. C. Brade 19634 (RB); PERNAMBUCO: Igarassu, Campina dos Marcos, 26.VI.1955, fl. e fr., A. Lima 55-2081 (IPA); RIO GRANDE DO SUL: Cruz Alta, s.d., fl. e fr., G. O. A. Malme s.n. (C 142/98-21, R 20449); Pinhal, 12.XII.1987, fl. e fr., S. Tsugar et al. B2450 (NY); RORAIMA: Boa Vista, Serra Tepequem, 17.II.1967, fl. e fr., G. T. Prance et al. 4486 (NY, US); SANTA CATARINA: Chapecó, fazenda Campo São Vicente, 26-28.XII-1956, fl. e fr., L. B. Smith et al. 9477 (NY, US); Mafra, 2-4 km $\mathrm{S}$ de Mafra pela rodovia Federal, 2.II.1957, fl. e fr., L. B. Smith \& R. M. Klein 10662 (US); Palhoça, Campo Massiambu, 12.III.1953, fl. e fr., R. Reitz \& R. M. Klein 470 (US). SÃO PAULO: Araraquara, s.d., fl., L. Riedel 2308 (BR); Franca, s.d., fl. e fr., L. Riedel 2724 (BR n.v. - fotocópia UEC); São Paulo, Vila Mariana, 3.VI.1906, fl. e fr., A. Usteri s.n. (C). COLÔMBIA. Comisaria del Vaupés, margens do rio Imirida, 7.II.1953, fl. e fr., A. Fernandez 2198 (US); Los Llanos, rio Meta, 3.XI.1938, fl. e fr., J. Cuatrecasas 4360 (F, US); Meta, Villa Vicencio, 26-31.VIII.1917, fl. e fr., F. W. Pennell 1415 (NY, US). GUATEMALA. Chiquiumula, Montaña Castilla, 6.XI.1939, fl. e fr., J. A. Steyermark s.n. (F 1041235). GUIANA. Rupununi, Savana Rupununi, 17.IX.1963, fl. e fr., R. Goodland \& R. Persaud 789 (NY); Chaakoitou, próximo à Mountain Point, 25.X.1979, fl. e fr., P. J. M. Maas \& L. Y. Th. Westra 4024 
(NY); Kaieteur, 5.XII.1884, fl. e fr., E. F. Thurn 113 (BM, US). GUIANA FRANCESA. Kourou, Savana Kourou, 1987, fl. e fr., M. Freiberg 328 (B). HONDURAS. Comayagua, próximo à Siguatepeque, 14-27.II.1928, fl. e fr., P. C. Standley 56090 (F); Morazán, córrego Santa Clara, X.1949, fl. e fr., L. O. Willian \& A. Molinar s.n. (BM 571268). PANAMÁ. Pacora, 1938, fl. e fr., P. Allen 994 (US); Ilha Toboga, 30.X.1917, fl. e fr., E. Killip 3188 (US). PARAGUAI. Caaguazú, s.d., fl. e fr., E. Hassler 8874 (G); Serra Amambay, I.1907, fl. e fr., T. Rojas 10750 (BM, G); Vila Lana, rio Apa, I.1908, fl. e fr., K. Fiebrig 5250 (G, L, M, US). VENEZUELA. Táchira, Uribante, Cerro El Morro, 16.XI.1988, fl. e fr., R. Ribeiro et al. 2009 (NY). SURINAME. Savana Sipaliwini, 24.VIII.1966, J. Donselaar 3545 (US).

Aublet (1775) descreveu Exacum tenuifolium com base em coletas da Guiana Francesa, porém não cita o número da coleta, nem faz qualquer outra menção sobre o material. Sendo assim, após grande procura nos herbários internacionais, estabeleceu-se a ilustração de sua obra como lectótipo. Ressaltando-se, entretanto, que a ilustração mostra uma flor tetrâmera com filetes exsertos, características ausentes em Curtia. As demais características, assim como a ilustração do hábito, no entanto, sustentam a figura de Aublet (1775) como lectótipo. Equívocos na ilustração da flor no trabalho de Aublet (1775) foram anteriormente observadas por Benthan (1839), o qual sugere que uma mistura de materiais de Coutoubea Aubl. ou Schultesia Mart. provavelmente tenha levado a uma descrição equivocada da flor.

Don (1839) transferiu Exacum tenuifolium Aubl. para Schuebleria tenuifolia e Grisebach (1839) descreveu um novo gênero, Apophragma, para incluir esta espécie. Segundo Grisebach (1839), seu novo gênero estava baseado na descrição de Aublet (1775) para E. tenuifolium, nos comentários de G. Don (1839) para S. tenuifolia e no exame de um material seco e destituído de flores coletado por Schomburgh, sem número de coletor ou indicação de herbário. Martius, em 1827, descreveu Schuebleria patula, com base em suas coletas de Serro (Minas Gerais) e em coletas de Pohl, de Goiás. Com base na descrição, ilustração e fotocópia dos materiaistipo, nas quais os estigmas longos podem ser observados persistentes nas cápsulas maduras, foi possível verificar que o autor se baseou em espécimes longistilos para a descrição da espécie. A ocorrência de heterostilia nesta espécie e as variações na coloração da corola e no tamanho das flores explicam os sinônimos. A descrição e a ilustração de Arechavalleta (1910) para C. montevidensis não deixam dúvidas quanto sua sinonimização em $C$. tenuifolia, apesar de não ter sido possível localizar seu material-tipo.

Curtia tenuifolia está amplamente distribuída, tendo sido coletada na Argentina, em todas as Regiões do Brasil, Colômbia, Guatemala, Guiana, Guiana Francesa, Honduras, Panamá, Paraguai, Suriname, Uruguai e Venezuela; em cerrados, savanas e campos rupestres, em altitudes de 90 a 1.600 m. Floresce e frutifica o ano todo.

8. Curtia verticillaris (Spreng.) Knobl., Bot. Centralbl. 60(11): 357. 1894. Sabatia verticillaris Spreng., Syst. veg. 1: 580. 1825. Curtia gentianoides Cham. \& Schltdl., Linnaea 1: 210; tab. 4, fig. 2. 1826, nom. superfl. Tipo: BRASIL. BAHIA: Caravelas, F. Sellow s.n. (lectótipo CGE n.v., aqui designado fotografia UEC). $\quad$ Figs. 11, 12

Schuebleria stricta Mart., Nov. Gen. sp. pl. 2: 116; tab. 187. 1827. Tipo: BRASIL. MINAS GERAIS: Diamantina, V-VI.1818, C. F. P. Martius s.n. (holótipo M n.v. - fotocópia UEC).

Ervas, 29-130 cm alt.; caule verde ou vináceo, 6-14-angulado, 1,2-4 mm diâm.; entrenós 4-30 mm compr. Folhas 4-7 por nó, 5,5-15 × 2-8 mm, verdes ou vináceas, oblongas (estreito-oblongas ou loradas), elípticas (amplo-elípticas, elípticas ou estreitoelípticas) ou ovadas (lanceoladas, estreitoovadas ou ovadas), ápice agudo ou acuminado; profilos 0,8-8 ×0,5-5 mm. Flores, 7,5-14 mm compr., homostílicas; pedicelo 1,5-8,5 mm 


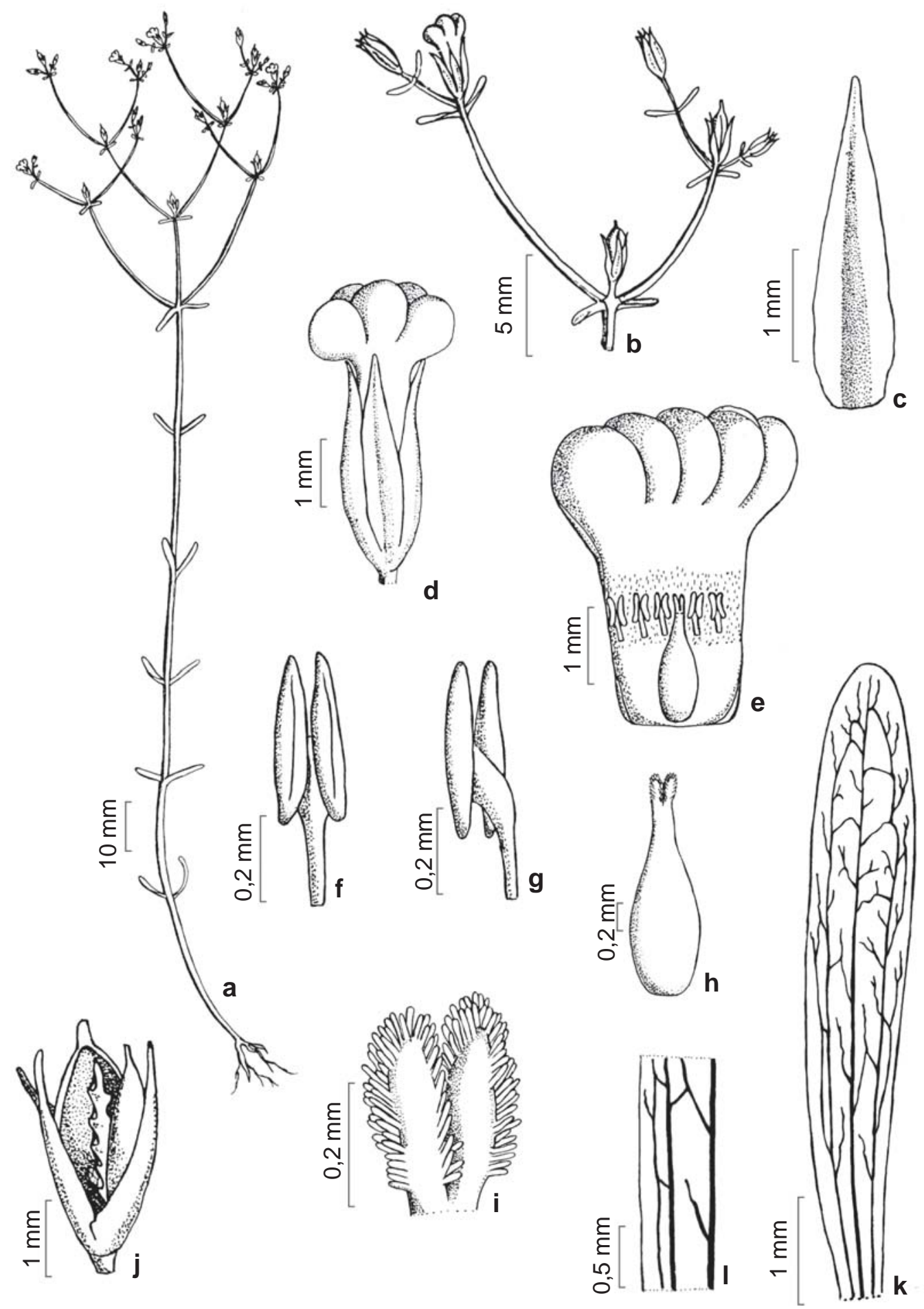

Figura 7 - Curtia tenella (Mart.) Cham. - a. hábito; b. inflorescência; c. sépala; d. flor; e. flor em seção longitudinal; f. estame, vista ventral; g. estame, vista dorsal; h. gineceu; i. estigma; j. fruto deiscente; $k$. folha, venação; l. detalhe da rede de venação. (Warming 1118a, C)

Figure 7 - Curtia tenella (Mart.) Cham. - a. habit; b. inflorescence; c. sepal; d. flower; e. flower, longitudinal section; f. stamen, ventral view; g. stamen, dorsal view; h. gynoecium; i. stigma; j. dehiscence fruit; k. leaf, venation; l. detail of the venation system. (Warming 1118a, C) 


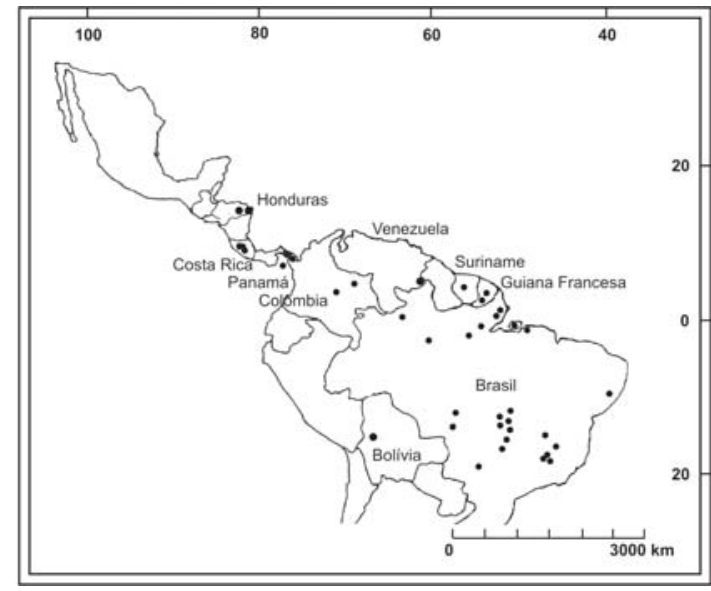

Figura 8 - Mapa de distribuição geográfica de Curtia tenella (Mart.) Cham.

Figure 8 - Geographic distribution of Curtia tenella (Mart.) Cham.

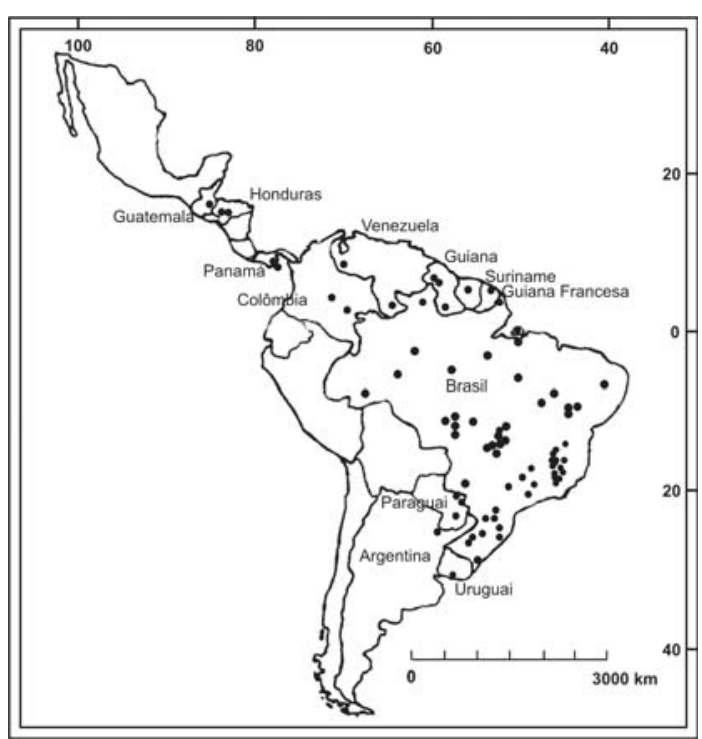

Figura 9 - Mapa de distribuição geográfica de Curtia tenuifolia (Aubl.) Knobl.

Figure 9 - Geographic distribution of Curtia tenuifolia (Aubl.) Knobl.

compr., verdes ou vináceos. Sépalas, 2,6-4,8 $\times 1-1,5 \mathrm{~mm}$, verdes ou vináceas, lanceoladas ou estreito-ovadas, ápice acuminado, alcançando próximo à região mediana do tubo corolino ou, mais frequentemente, abaixo dela, margens denticuladas. Corola tubulosa, infundibuliforme, branca, rosa, lilás, azul ou roxa, sendo frequentemente, os botões e as
Crespo, S. R. M. \& Marcondes-Ferreira, W.

flores jovens azuis até roxos passando a róseos, lilás ou brancos; tubo 6,3-9,5 mm compr., glabro; lobos 1-4,5 mm compr., ovados, ápice acuminado, agudo ou obtuso. Androceu com filetes de 2,4-5,8 $\times 0,12-0,15 \mathrm{~mm}$, inseridos no terço inferior do tubo corolino ou próximo à sua base; anteras 1-1,4 mm compr., livres, introrsas, conectivo das anteras prolongado $30-100 \mathrm{~mm}$ acima das tecas, inteiro. Gineceu 5-9,5 mm compr.; ovário oblongo ou ovado; estigma 0,51 mm compr., capitado; papilas estigmáticas 20$50 \times 17-40 \mathrm{~mm}$, oblongas. Cápsulas 6-10 mm compr., oblongas.

Material examinado: BRASIL. BAHIA: Abaíra, Serra do Atalho, 18.IV.1994, fr., E. Melo et al. 1016(HUEFS); ibid., Catolés, caminho Guarda Mor para Cristais, 7.IV.1992, fl. efr., W. Ganev 62 (HUEFS, UEC); Andaraí, Serra de Andaraí, 30.X.1978, fl. e fr., G. Martinelli et al. 5443 (RB); Campo Formoso, Cachoeira do Buraquinho, 21.X.1991, fl. e fr., N. L. Menezes et al. 1271 (SPF); Lençóis, 30.I.1983, fl. e fr., N. S. Santos 15747 (HUEFS); Morro do Chapéu, 30.VIII.1990, fl. e fr., J. L. Hage et al. 2312 (HUEFS); Mucugê, Serra do Capa Bode, estrada para Andaraí, 30.X.1978, fr., G. Martinelli 5404(RB); Palmeiras, Caeté-Açu, Cachoeira Glass, 30.VI.1983, fl. e fr., L. P. Queiroz 679 (HUEFS); Rio de Contas, 4 km N de Rio de Contas, 21.VII.1979, fl. e fr., S. Mori et al. s.n. (NY, UB 12375, US 2856963); ibid., Pico das Almas, 23.VII.1979, fl. e fr., J. L. Hage et al. s.n. (RB 202231); Serra Carrasca, 1914, fl. e fr., Lutzelburg 114(M); DISTRITO FEDERAL: Brasilia, córrego Cabeça de Veado, 9,5 km SSE de Brasília, 3.VI.1976, fl. e fr., J. Ratter s.n. (UB 25471); GOIÁS: Chapada dos Veadeiros, $20 \mathrm{~km}$ ao Norte de Alto do Paraíso de Goiás, 19.III.1971, fl. e fr., H. S. Irwin et al. s.n. (C 142/98-35, F 1772780, UB 25460, US 2709798,); Cristalina, Linda Serra dos Topázios, 3.VI.1996, fl. e fr., R. Oliveira \& C. Proença 1266 (UB); Pirenópolis, Pico dos Pireneus, 26.I.1968, fl. e fr., H. S. Irwin et al. 19241 (NY, UB); Serra dos Cristais, 2.III.1966, fl. e fr., H. S. Irwin et al. 13246 (NY, UB); MINAS GERAIS: Buenópolis, Serra do Cabral, 3.IX.1949, fl. e fr., M. Magalhães 4401 (BHCB); Catas Altas, Serra da Caraça, s.d., fl. e fr., A. F. M. Glaziou 15245 (BM, BR, R); Diamantina, Serra do Rio Grande, 12.V.1931, fl. efr., Y. Mexia 5817 (BM, F, M, NY, R, US); Gouveia, Serra do Espinhaço, 3.II.1972, fl. e fr., W. Anderson et al. s.n. (UB 27104); Grão Mogol, Serra do Grão Mogol, 12.XI.1938, fl. e fr., F. Markgraf et al. 3472 (RB); Itamarandiba, Serra do Ambrósio, Espigão do Meio, 8.IX.1986, fl. e fr., I. Cordeiro et al. 10210 (UEC); 


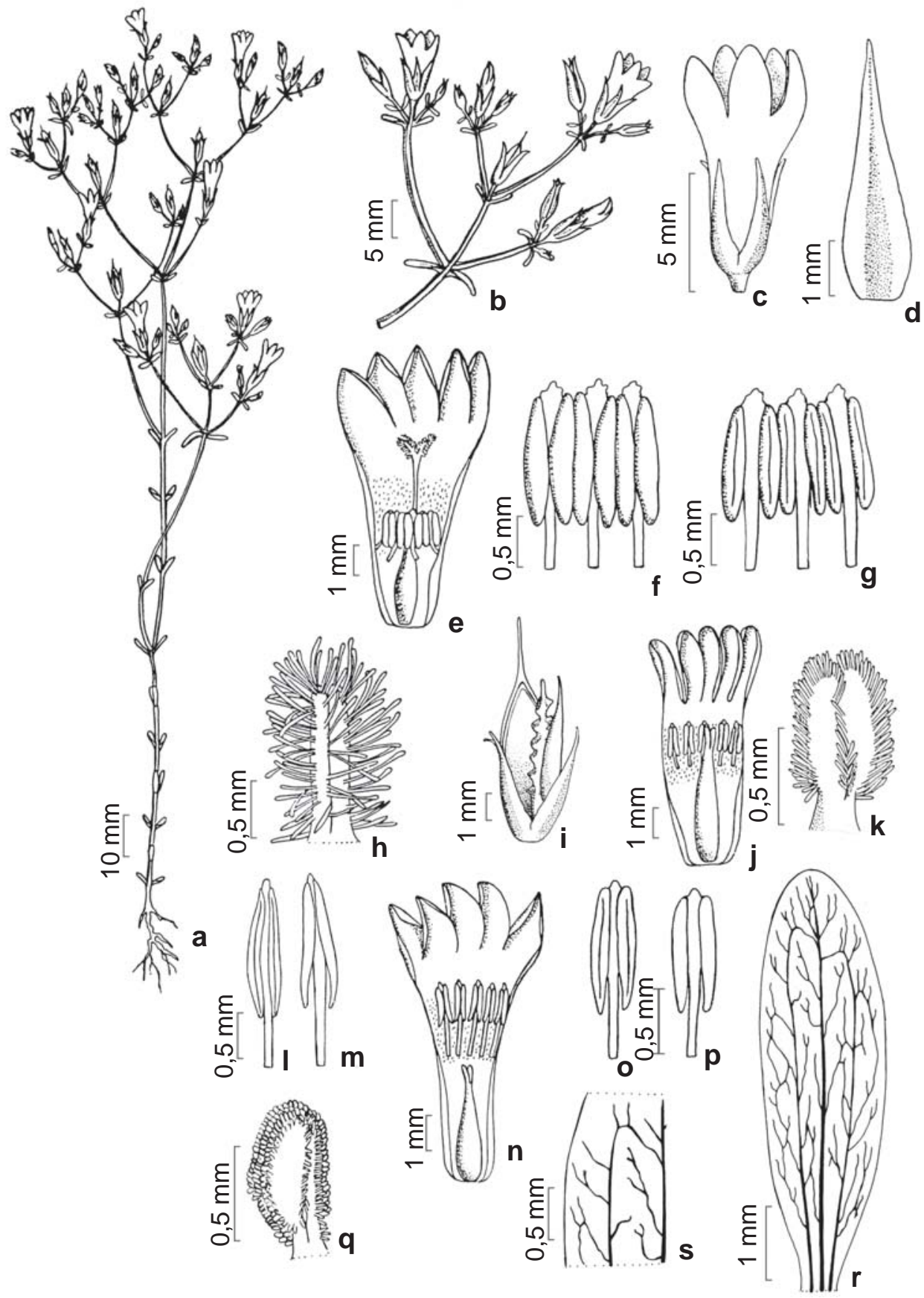

Figura 10 - Curtia tenuifolia (Aubl.) Knobl. - a-i. flor longistila - a. hábito; b. inflorescência; c. flor; d. sépala; e. flor em seção longitudinal; f. estames, vista ventral; g. estames, vista dorsal; h. estigma; i. fruto deiscente. j-m. flor mesostila - j. flor em seção longitudinal; k. estigma; l. estame, vista ventral; m. estame, vista dorsal. n-q. flor brevistila - n. flor em seção longitudinal; o-p. estame, vista ventral; q. estigma. r-s. folha - r. folha, venação; s. detalhe da rede de venação. (a-i Irwin et al. 1 7433a, IAN; j-m Malme, C142/98-21; n-q Anderson 8125a, UB; r-s Feres \& Crespo 99/44, UEC)

Figure 10 - Curtia tenuifolia (Aubl.) Knobl. - a-i. long-styled flower - a. habit; b. inflorescence; c. flower; d. sepal; e. flower, longitudinal section; f. stamens, ventral view; g. stamens, dorsal view; h. stigma; i. dehiscence fruit. j-m. medium-styled flower - j. flower, longitudinal section; k. stigma; l. stamen, ventral view; m. stamen, dorsal view. n-q. short-styled flower - n. flower, longitudinal section; o-p. stamen, ventral view; q. stigma. r-s. leaf - r. leaf, venação; s. detail of the venation system. (a-i Irwin et al. 1 7433a, IAN; j-m Malme, C142/98-21; n-q Anderson 8125a, UB; r-s Feres \& Crespo 99/44, UEC) 


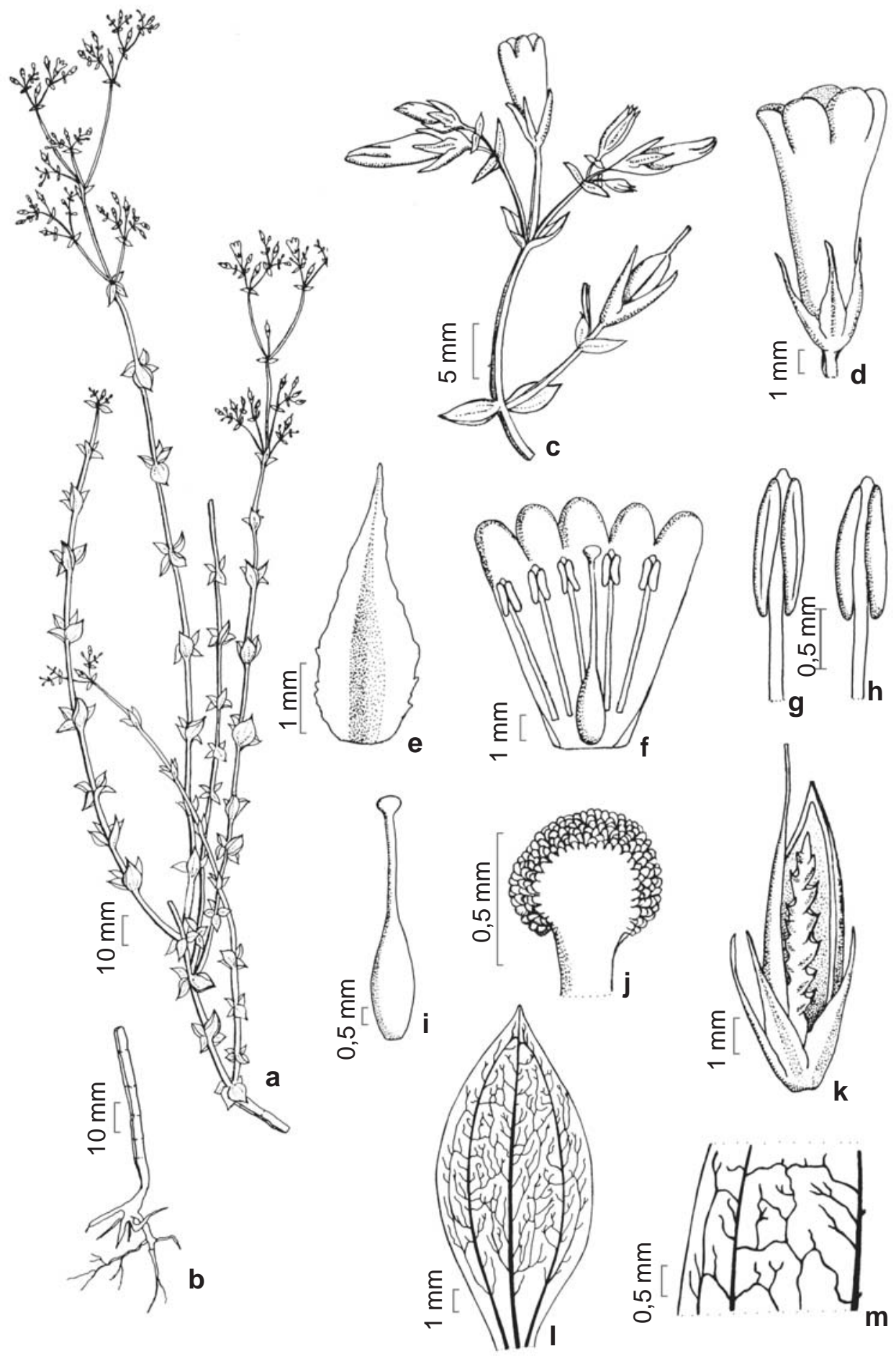

Figura 11 - Curtia verticillaris (Spreng.) Knobl. - a. hábito; b. porção basal do caule e raiz; c. inflorescência; d. flor; e. sépala; f. flor em seção longitudinal; g. estame, vista ventral; h. estame, vista dorsal; i. gineceu; j. estigma; k. fruto deiscente; l. folha, venação; m. detalhe da rede de venação. (Anderson et al. s.n., UB 27104)

Figure 11 - Curtia verticillaris (Spreng.) Knobl. - a. habit; b. basal portion of stem and root; c. inflorescence; d. flower; e. sepal; f. flower, longitudinal section; g. stamen, ventral view; h. stamen, dorsal view; i. gynoecium; j. stigma; k. opened fruit; l. leaf, venation; m. detail of the venation system (Anderson et al. s.n., UB 27104) 


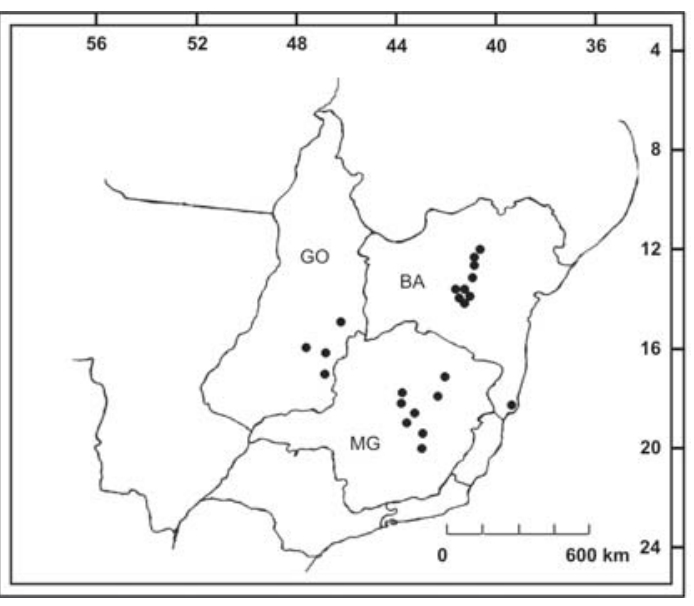

Figura 12 - Mapa de distribuição geográfica de Curtia verticillaris (Spreng.) Knobl.

Figure 12 - Geographic distribution of Curtia verticillaris (Spreng.) Knobl.

Joaquim Felício, 17.IV.1981, fl. e fr., L. Rossi et al. 1169 (UEC); Santana do Riacho, 6 km N do Palácio, 29.IV.1952, fl. e fr., L. B. Smith et al. 6884(NY, R, US); ibid., Palácio, Serra do Cipó, 20.II.1968, fl. e fr., H. S. Irwin et al. 20545 (NY, UB); ibid., Serra do Cipó, 18.II.1972, fl. e fr., W. Anderson et al. 36177 (UB);

Sprengel (1825) descreveu Sabatia verticillaris com um breve texto e Chamisso \& Schlechtendal (1826), baseados no mesmo material, descreveram Curtia gentianoides, apresentando um detalhado texto e ilustrações da flor e do fruto. Como o holótipo não foi localizado, o isótipo depositado em CGE foi designado como lectótipo deste nome. A análise dos materiais de $C$. verticillaris demonstrou que essa espécie varia quanto ao comprimento dos filetes e à forma das folhas.

Distribui-se no Brasil, nos estados da Bahia, Goiás e Minas Gerais, além do Distrito Federal, em altitudes de 100 a 1.600 m. Floresce e frutifica o ano todo.

\section{Agradecimentos}

Aos professores da UNICAMP, Departamento de Botânica, pelo apoio e auxílio durante a realização desta pesquisa, aos funcionários e técnicos dos laboratórios de Sistemática e Biossistemática do Departamento de Botânica, pela ajuda nos procedimentos laboratoriais, à CAPES, pelo auxílio financeiro, aos curadores dos herbários consultados e cujo material foi enviado para empréstimo, ao Dr. Bruno Wallnoefer do Herbário W (Viena), pelo envio de fotografias de materiais-tipo, e ao Prof. Dr. Paulo Seda, pela busca de espécimes de Curtia em suas excursões.

\section{REFERÊNCIAS BIBLIOGRÁFICAS}

Arechavaleta, J. 1910. Flora uruguaia. Anales Del Museo Nacional de Montevideo 2(1): 65-66.

Aublet, J. B. C. 1775. Histoire des plantes de la Guiane Françoise. Vol. 1. PierreFrançois Didot jeune, Londres, Paris. Pp. 70-71.

Bentham, G. 1839. Enumeration of the plants collected by Mr. Schomburgk in British Guiana. Annals of Natural History 2(2): 441-443.

Chamisso, A. \& Schlechtendal, D. 1826. De plantis in expeditione speculatoria romanzoffiana observatis. Linnaea 1: 165-226.

Cobb, L.; Jansen-Jacobs, M. J. \& van der Han, R. W. J. M. 2007. Curtia ayangannae, a new species of Gentianaceae from the Pakaraima Mountains, Guyana. Blumea 52: 5-10.

Cordeiro, I. 1987. Flora da serra do Cipó, Minas Gerais-Gentianaceae. Boletim de Botânica da Universidade de São Paulo 9: 227-242.

Crespo, S. R. M. 2003. Revisão taxonômica do gênero Curtia Cham. \& Schltdl. (Gentianaceae Juss.). Tese de Doutorado. Universidade Estadual de Campinas, Campinas, 230p.

Crespo, S. R. M. \& Ferreira, W. M. 2006. Morfologia polínica dos gêneros Curtia Cham. \& Schltdl. e Hockinia Gardner (Gentianaceae Juss.). Acta Botanica Brasilica 20(2): 273-284.

Don, G. 1839. A general system of gardening and botany. Miller's gardeners's dictionary 4: 201-202. 
Elias, T. S. \& Robyns, A. 1975. Gentianaceae In: Woodson, R. E.; Schery Jr., R. W \& Collaborators (eds.). Flora of Panamá. Annals of the Missouri Botanical Garden 62: 61-101.

Fabris, H. A. \& Klein, R. M. 1971. Gentianaceae In: Reitz, R. (ed.) Flora ilustrada catarinense. Herbário Barbosa Rodrigues, Itajaí. Pp.1-30.

Fahn, A. 1990. Plant anatomy. 4.ed. Butterworh-Heinemenn. Pergamon Press, Oxford, 588p.

Gilg, C. 1938. Beiträge zur Kenntnis der Gentianaceen-Gattung Curtia Cham. \& Schltdl. Notizblatt des Botanischen Garten und Museum Berlin 14(121): 66-93.

Grisebach, A. H. R. 1839. Genera et species Gentianearum- observationibus quibusdam phytogeographicis. J. G. Cottae, Stuttgart, 364p.

Grisebach, A. H. R. 1845. Gentianaceae. In: Candolle, A. (ed.). Prodromus systematis naturalis regni vegetabilis. Vol. 9. Fortin, Masson et Sociorum, Paris. Pp. 38-141, 560-563.

Grothe, E. H. M. \& Maas P. J. M. 1984. A scanning electron microscopic study of the seed coat structure of Curtia Chamisso \& Schlechtendal and Hockinia Gardner (Gentianaceae). Proceedings of the Koninklijke Nederlandse Akademie van Wetenschappen 87(1): 33-42.

Hickey, L. 1973. Classification of the architeture of dicotyledonous leaves. American Journal of Botany 60(1): 17-33.
Johansen, D. A. 1940. Plant microtechnique. Mc Graw-Hill Book Co. Inc., New York. 523p.

Knoblauch, E. 1894. Beiträge zur Kenntniss der Gentianaceae. Botanisches Centralblatt 60(11): 321-401.

Maguire, B. 1981. Gentianaceae In: Maguire, B. \& Collaborators (eds.). The botany of Guayana Highland - Part. XI. Memoirs of the New York Botanical Garden 32: 330-388.

Martius, C. F. P. 1827. Nova genera et species plantarum. Vol. 2. Typis Lindaueri, Monachii. Pp. 69-148.

Metcalfe, C. R. \& Chalk. L. 1979. Anatomy of dicotyledons. Systematic anatomy of the leaf and stem. Oxford Science publications, Claredon Press, Oxford, 276p.

Progel, A. 1865. Gentianaceae. In: Martius, C. F. P. (ed.). Flora brasiliensis vol. 6, pars 1. F. Fliescher, Monachii. Pp. 202-248, t. 55-60.

Sprengel, K. P. J. 1825. Gentianaceae. Systema vegetabilium (ed. 16). Vol. 1. Sumtibus Librariae Dieterichianae, Gottingae, 580p.

Stearn, W. T. 1992. Botanical Latin - History, grammar, sintax, terminology and vocabulary. David \& Charles, London, 566p.

Struwe, L. \& Albert, V. A. (ed.). 2002. Gentianaceae - Systematics and natural history. Cambridge University Press, Cambridge, 652p.

Weberling, F. 1992. Morphology of flowers and inflorescences. Cambridge University Press, Cambridge, 405p. 